\title{
Experimentelle Untersuchungen ïber nervöse Reflexe von verschiedenen organen und peripheren Nerven auf den Uterus.
}

Von

\author{
Professor Dr. E. Kehrer-Heidelberg. \\ (Hierzu Tafel III-VIII und 5 Textfiguren.)
}

Die wechselseitigen reflectorischen Beziehungen zwischen Uterus und anderen Organen sind dem Kliniker lange bekannt. Aber die Vorstellungen über ihren Entstehungsmechanismus und über die von ihnen in Anspruch genommenen Nervenwege sind unklar geblieben, wie vordem. Wir wissen, dass Genitalerkrankungen allgemeine Neurosen auslösen können, unter der Voraussetzung eines von früher her geschwächten, "labilen" Nervensystems, und dass es psychische Reflexe von den Genitalien aus giebt, welche unbewusst das Seelenleben beeinflussen und beherrschen. Schon ältere Autoren gebrauchten die Bezeichnung "Tussis uterina" für einen krampthaften Husten, der als Reflex von den Genital- auf die Respirationsorgane aufgefasst wurde - gleich dem Husten, der nach Reizung des Gehörgangs oder nach Naunyn (1) durch Palpation erkrankter Organe: Leber, Magen und Milz zuweilen ausgelöst werden kann. In gleicher Weise wurden Asthma, Dyspnoe und Tachypnoe als Reflexneurosen der Athmungsorgane, Tachycardie und andere Erscheinungen des Circulationssystems als Reflexneurosen des Herzens beschrieben.

Lange bekannt sind die reflectorischen Beziehungen zwischen Brustdrüsen und weiblichen Genitalien. Wenn auch heute auf Grund zahlreicher Versuche, vor Allem englischer Autoren, feststeht, dass das Wachsen der Brustdrüsen während der Schwangerschaft durch die Production einer chemischen Substanz geschieht, eines, wahrscheinlich im wachsenden Embryo gebildeten Hormons im Sinne von Bayliss und Starling (2), so hat man bisher doch nicht 


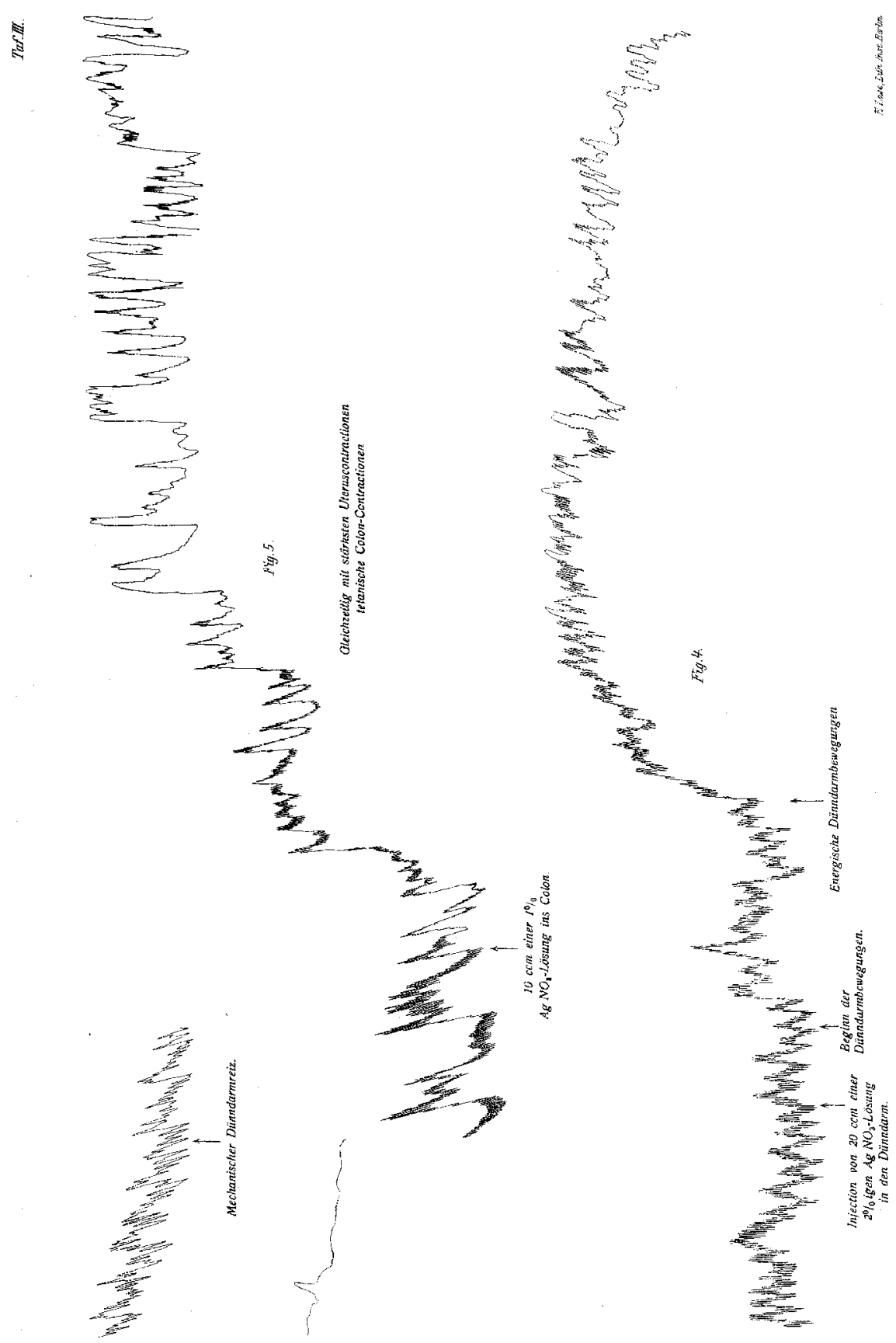


है

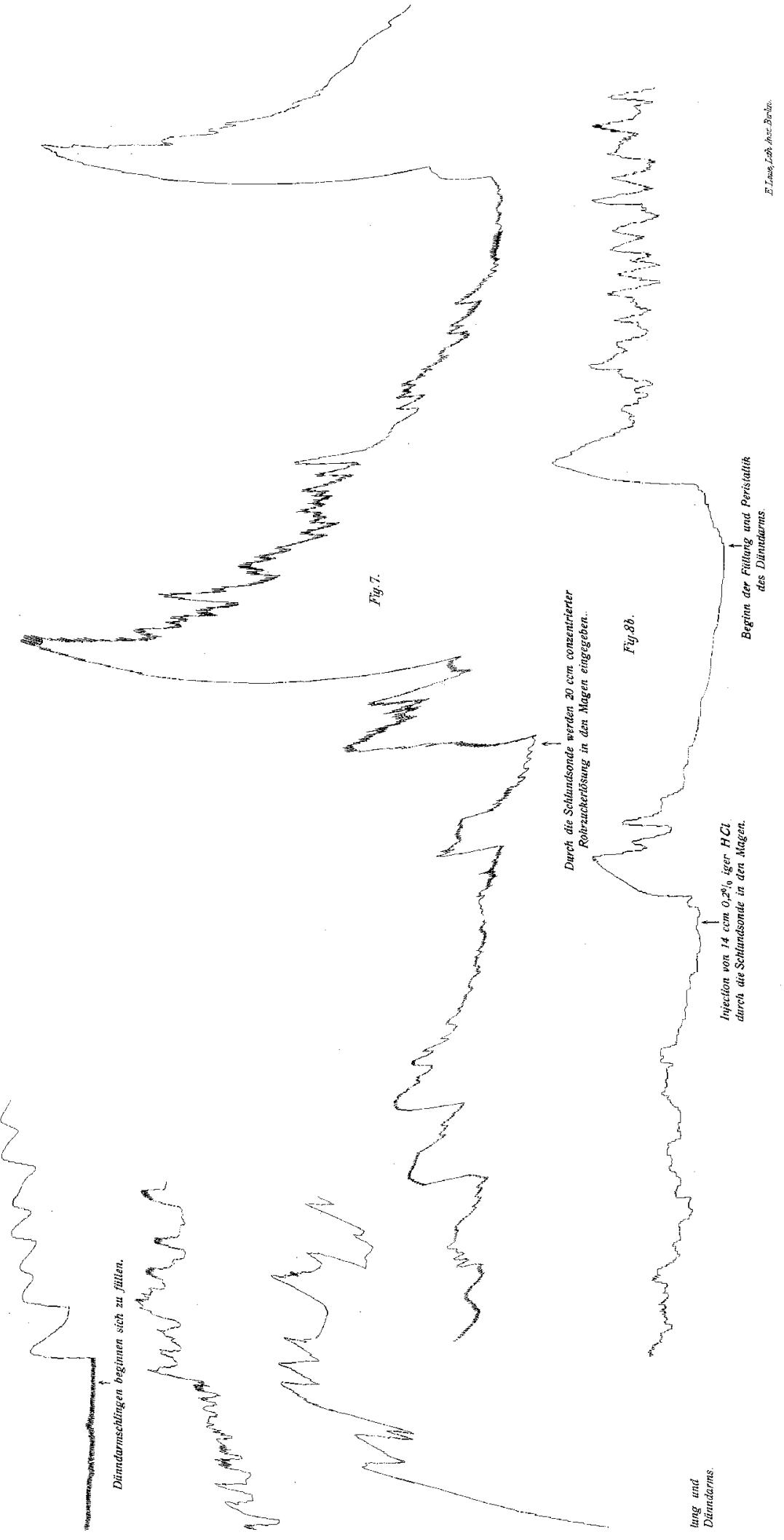


sั

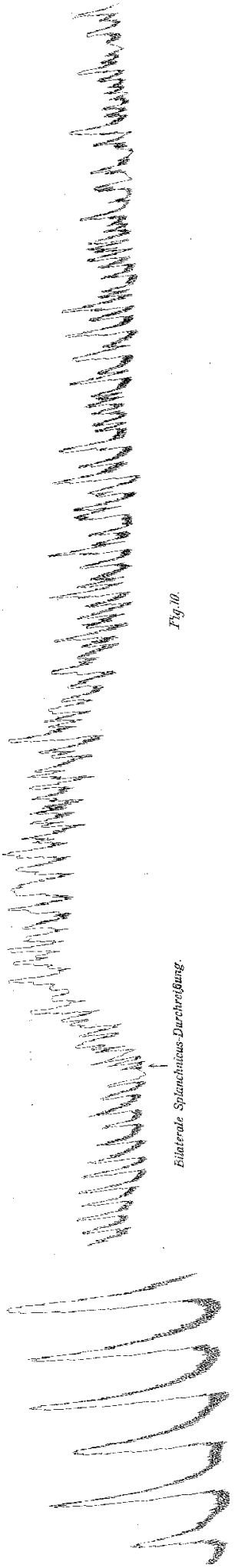

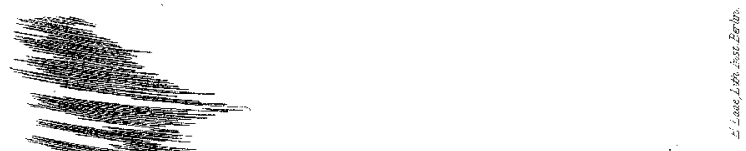

a

구의

nond

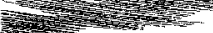

$\sum$

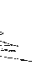

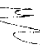

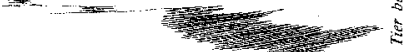

제

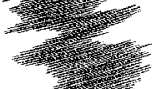

管
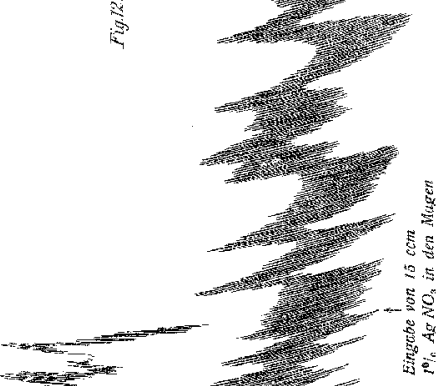

날
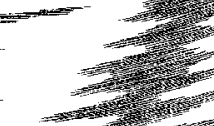

(2)
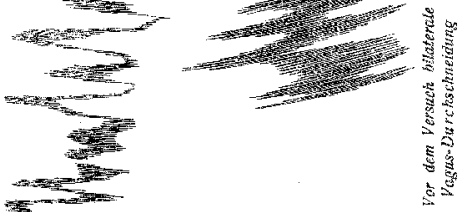

年

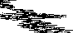

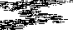

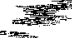

$x=$
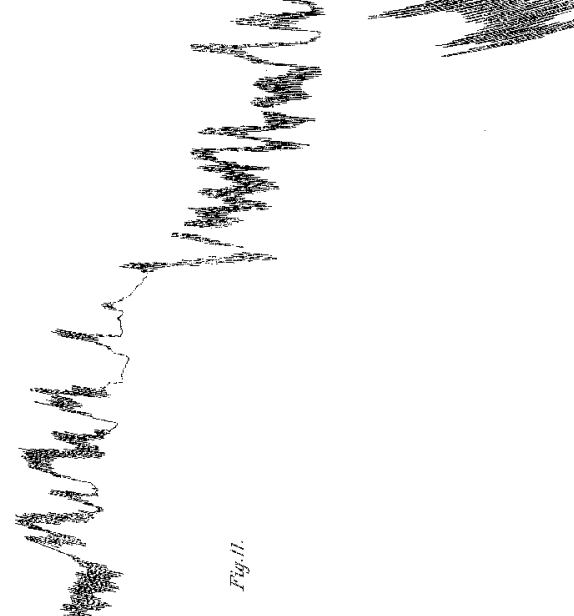

$\rightarrow$
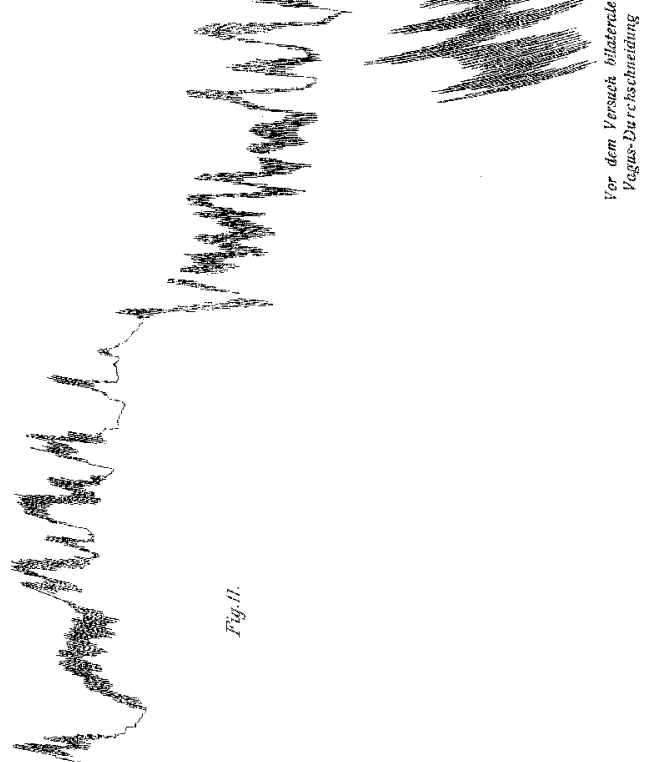

瓷

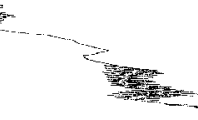

$+$ 


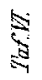

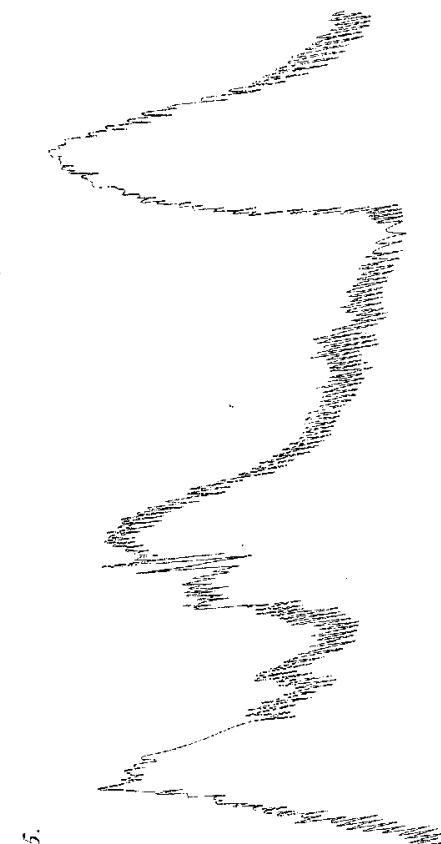

is

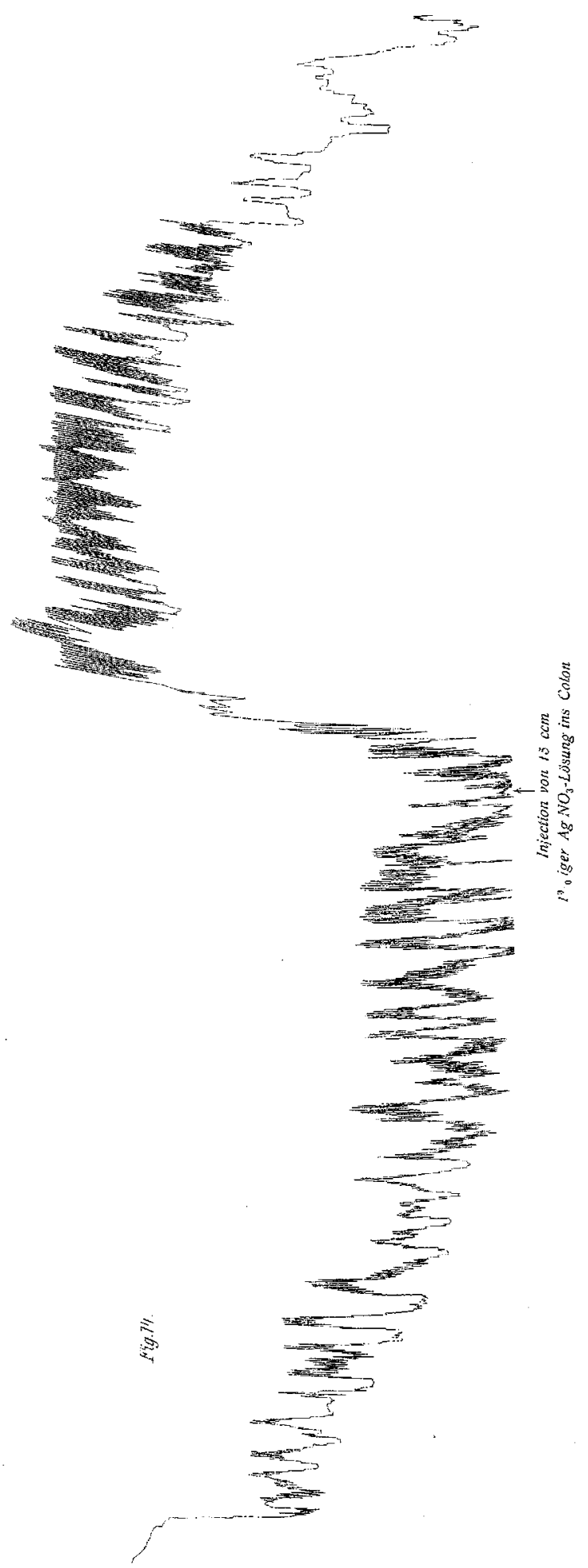


s
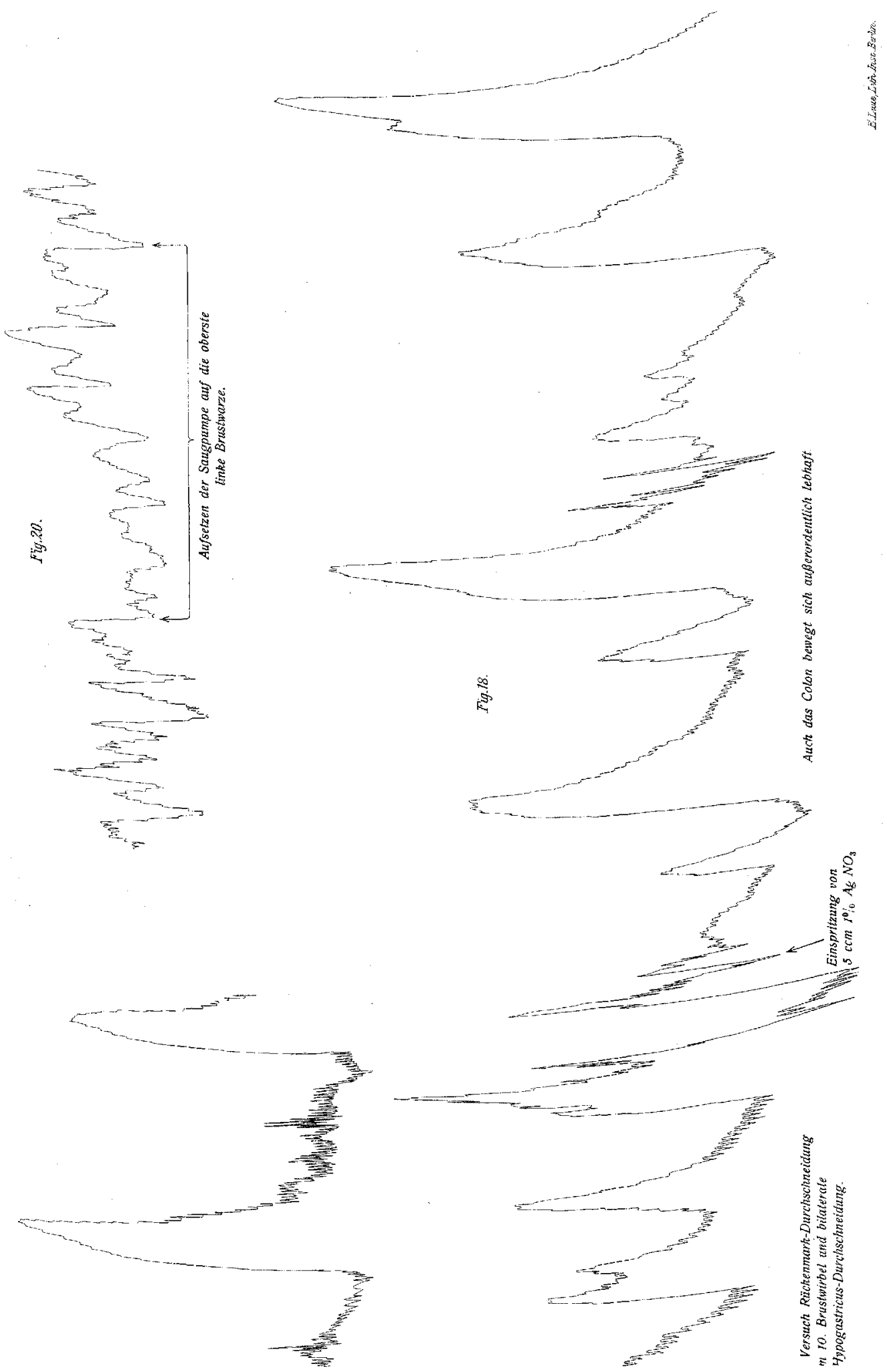


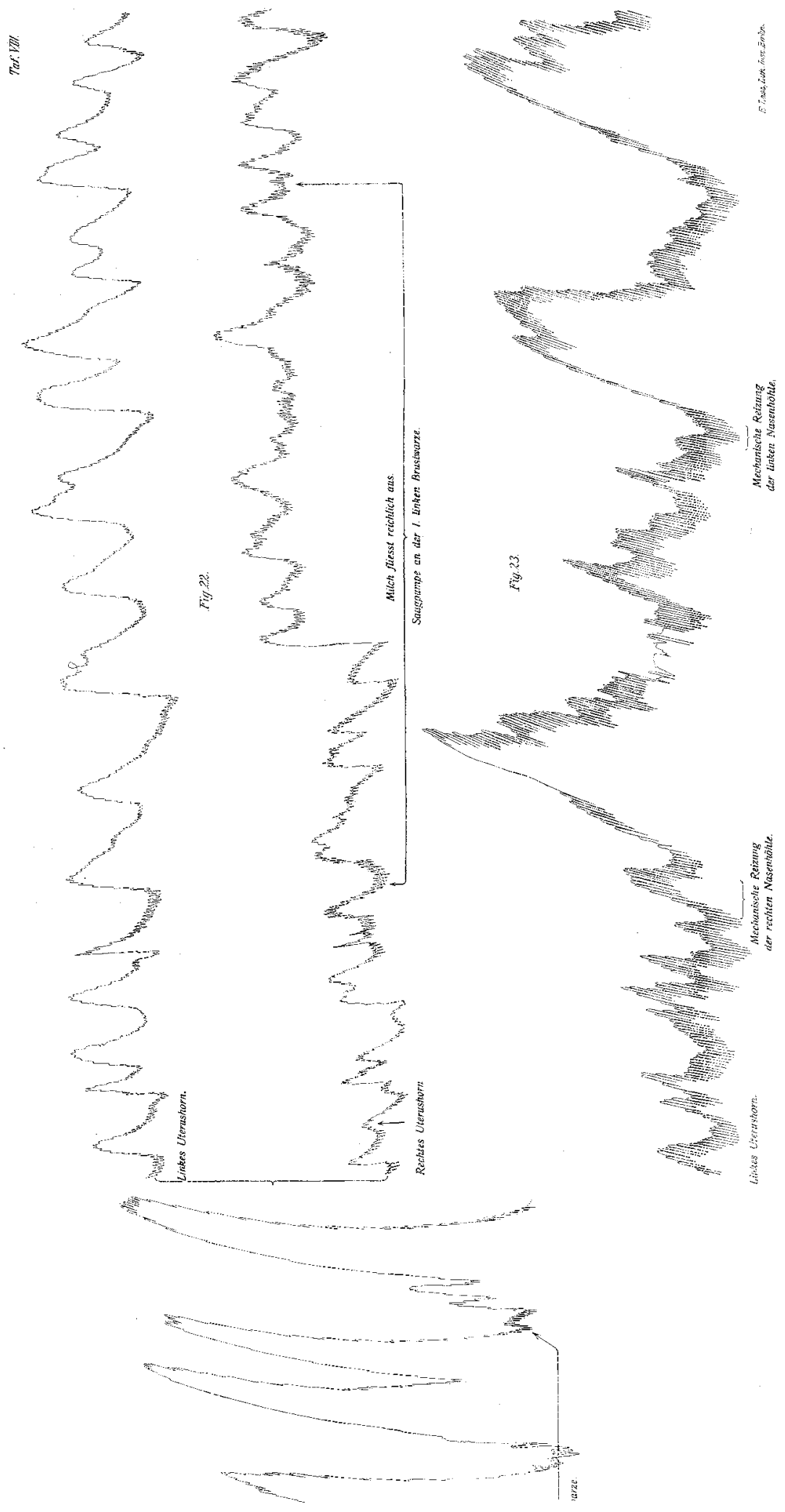


daran gezweifelt, dass neben diesen chemischen auch nervöse Beziehungen zwischen Genitalapparat und Brustdrüsen bestehen.

Es scheint festzustehen, dass Veränderungen in den Generationsorganen, besonders solche im Uterus und den Ovarien Schmerzen in den Brustdrüsen auslösen können, die zur Zeit der Menstruation zu exacerbiren pflegen.

Umgekehrt kennen wir Thatsachen, welche zu zeigen scheinen, dass auch von den Brustdrüsen aus die Genitalsphäre beeinflusst werden kann. Leichte mechanische Reize der Brustwarze vermögen bei manchen Frauen - wenigstens bei einer gewissen Gemüthsstimmung - Wollustempfindungen, Erection der Clitoris, Contraction der Musculatur des Beckenbodens, vermehrte Absonderung der Bartholin'schen Drüsen und der Vorhofschleimdrüsen hervorzurufen [Busch (3), Max Pfister (4)].

Saugen an den Brustwarzen pflegt nicht nur am puerperalen, sondern auch am schwangeren Uterus Contractionen, oft subjectiv und schmerzhaft wahrnehmbar, auszulösen. Diese Erfahrung hatte schon Hippocrates (5) zu dem Rathe veranlasst: "wenn man bei einer Frau die monatliche Reinigung stillen will, so setze man einen möglichst grossen Schröpfkopf anf die Brüste", und auf sie gründet sich die alte Scanzoni'sche (6) Methode zur Einleitung der Frühgeburt. Scanzoni gebrauchte schröpfkopfartige Instrumente, Max Pfister (4) die einfachen Sauggläser mit Gummiballon, H. W. Freund (7) construirte einen elektrischen Saugapparat, den sogen. "elektrischen Schröpfkopf", bei dem die mechanische Wirkung des Schröpflopfes mit der des elektrischen Stromes combinirt zur Anwendung kam. Mollath (8) und die genannten Autoren wollen nicht nur Zusammenziehungen der Gebärmutter, sondern manchmal auch eine regelmässige, zur Geburt führende Wehenthätigkeit mit diesen Methoden hervorgerufen haben. Aber die Unsicherheit der Wirkung veranlassten schon Scanzoni diesen zur Frühgeburtseinleitung empfohlenen Verfahren den Rücken zu kehren.

Durch die von der Brust reflectorisch ausgelösten Uteruscontractionen erklärt man die gnte Rückbildung des Uterus bei stillenden Frauen, während umgekehrt die Subinvolution des Uterus bei nicht stillenden Wöchnerinnen hauptsächlich auf das Fehlen des Saugactes zurückgeführt wird.

Die Beziehungen zwischen Uterus und Magendarmcanal wurden mehr von den älteren Geburtshelfern als von unserer 
jetzigen Generation betont. Bei starker Füllung des Magens ist die Wehenthätigkeit bei der Geburt ungenügend: Plenus venter non parit libenter [F. A. Kehrer (9), Clemens]. Diese Erkenntniss führte in früherer Zeit zum Gebrauch der Emetica bei der Geburt, an deren Stelle noch heute die Magenausheberung und -Ausspülung mit Erfolg angewendet werden kann.

Analoge Verhältnisse bestehen beim Darm. Gründliche Entleerung der unteren Darmabschnitte bessert die atonischen Wehen besonders in der Eröffnungsperiode. Darauf hat neuerdings wieder Walthard (10) in v. Winckel's Handbuch der Geburtshülfe aufmerksam gemacht.

Wird die Darmperistaltik ausserordentlich gesteigert durch Gifte, die zufällig in den Magen Schwangerer gelangen oder als Abortiva angewandt werden, so soll eine Unterbrechung der Schwangerschaft auch bei Ausschluss einer nennenswerthen Resorptionswirkung erfolgen können.

Auch die häufigen Fälle, in denen Darmträgheit und Hyperämie des Uterus zu gleicher Zeit bestehen: Meteorismus im Anfang der Menstruation, auf der Hochzeitsreise und im Beginn der Schwangerschaft, im Frühwochenbett, besonders nach langdauernder schwerer Geburtsarbeit oder nach tetanischer Wehenthätigkeit, im Spätwochenbett bei ungenügender Rückbildung des Uterus, weisen auf die nahen Beziehungen der motorischen Functionen von Uterus und Magendarmeanal hin. Wo hier die primäre Ursache zu suchen ist, ob im Magen und Darm oder im Uterus, wissen wir noch nicht.

Aehnliche Verhältnisse, wie zwischen Darm und Uterus, scheinen auch zwischen ihm und der Harnblase $z u$ bestehen. Wenigstens. ist für die Fälle von ungenügender Rückbildung oder Retroflexion des puerperalen Uterus die Annahme einer durch die langdauernde Blasenfüllung reflectorisch ausgelösten Parese der Uterusmusculatur gestattet. Der gleiche Vorgang spielt vielleicht eine Rolle in der Aetiologie der Retrodeviationen überhaupt.

Die Nase steht in wechselseitigen reflectorischen Beziehungen zu den Genitalien. Das zeigt die nicht selten zu Epistaxis führende Hyperämie der Nasenschleimhaut und besonders der Muscheln bei. allen byperämischen Zuständen des Genitalapparates: bei Masturbation, Cohabitation, Menstruation (Mackenzie 1884) und Schwangerschaft. Das beweisen auch die Beziehungen zwischen Dysmenorrhoe 
und Hyperästhesie der sogen. Genitalstellen der Nasenschleimhaut. Diese, beiderseits am vorderen Ende der unteren Muschel uud am Tuberculum septi gelegen, sollen bei schmerzhafter Periode eine auffallende Empfindlichkeit auf leise Sondenberührung zeigen.

Eine reflectorische Abhängigkeit der Uterusbewegungen von der Nase soll nach Fliess (11) und Amann bestehen. Fliess behauptet, man könne von der Nase aus z. B. durch Galvanokaustik unter Umständen Abortus arteficialis herbeiführen. Amann hat nach Roith's (12) Angabe bei der Laparotomie einen sogen. gekreuzten Nasen-Uterusreflex in Form von Contraction der gegenseitigen Uterushälfte und des ihr entsprechenden Lig. rotundum gesehen, als er mechanische und chemische Reize auf die untere Muschel einwirken liess.

Endlich gehören in das Capitel der Genitalreflexe auch Reize, die von den Sinnesorganen, von Auge, Nase und Ohr durch das Grosshirn und wohl die Medulla oblongata auf die Schwellkörper des Genitalapparates und die Dammmusculatur übertragen werden, und analoge Reflexe dürften auch auf den Uterus erfolgen. Ich erwähne hier die Erection bei beiden Geschlechtern gelegentlich sinnlicher Vorstellungen und Vergnügungen, die Erection männlicher Thiere beim Geruch von Moschus oder von Secreten der Vorhofdrüsen bei der Brunst. Selbst bei grosshirnlosen Thieren und bei Hunden, die rom Rückenmark nur noch das Lumbalund Caudalmark besassen, konnte Goltz (13) Dank der Geschicklichkeit seines Laboratoriumdieners noch Erectionsreflexe auslösen. Entgrosshirnte Täuber besassen in Max Schrader's (14) Versuchen noch Geschlechtstrieb, wenn sie auch ruit dem Weibchen nicht in Beziehung traten, weil sie dasselbe als solches nicht zu erkennen vermochten.

Soweit die wenigen, meist empirisch festgelegten Thatsachen über die wechselseitigen reflectorischen Beziehungen zwischen Uterus und anderen Organen. Auf breiter Basis wurde eine experimentelle Untersuchung dieser Reflexe noch nicht vorgenommen. Nur für die Relationen zwischen Brustdrüse und Uterus und Nase und Uterus wurde eine experimentelle Begründung versucht.

Ich berichte in dieser Arbeit nur über Reflexe von versehiedenen Organen und von peripheren Nerven auf den Uterus und zunächst: 


\section{Ueber Reflexe vom Magen und Darm auf den Uterus.}

Ich begann meine Versuche an dem in körperwarmer physiologischer Kochsalzlösung oder besser in der bekannten Ringerschen Flüssigkeit laparotomirten Thier. Nach einer Versuchsanordnung, die ich (15) früher beschrieben habe, registrirte der Uterus von Katze und Kaninchen autographisch seine Bewegungen auf der rotirender Trommel des Kymographions. Wurde bei dem unter Aethernarkose und künstlicher Respiration gehaltenen Thier ein einfacher mechanischer Reiz am Magen oder Darm angewendet, so konnte gleichzeitig eine geringe Yerstärkung der rbythmischen pendelförmigen Bewegungen bemerkt werden, die nach meinen früheren Untersuchungen sowohl dem Uterushorn des lebenden nicht trächtigen Thieres wie dem überlebenden Organ charakteristisch sind.

Aber der auf das Grosshirn wirkende Aether musste das Studium der Reflexe - denn um solche konnte es sich wohl nur bandeln - erschweren. Nur wenn eine Methode sich finden liess, die die Reflexerregbarkeit des C. N. S. steigerte, waren deutliche Resultate za erhoffen. Nachdem sich ergeben batte, dass auch Urethan, durch die Schlundsonde in den Magen von Kaninchen gebracht, gleich dem Aether die Centralorgane lähmte, wurde die Reflexerregbarkeit bei Katzen durch die Injection kleiner Stryehnindosen erhöht. Aber die uteruserregende Wirkung des Strychnins addirt sich in diesen Fällen zu dem Effect der am Magendarmcanal angreifenden Reize.

Erst durch die Enthirnung nach der englischen, wohl von Sherrington zuerst angewandten Methode, deren Kenntniss ich Hern Professor Magnus verdanke, gelang es die Thiere in eine Art Reflexmaschine zu verwandeln, die in wunderbarer Weise auch auf subtile Reize mit deutlichen Ausschlägen reagirt. So erfolgen nicht selten klonische Zuckungen bei Prüfung der Sehnenreflexe oder bei Abkühlung des Thieres oder Abwehrbewegungen des Kopfes bei Berührung der Scbnurrhaare.

Die Decerebration an dem nach vorausgegangener Tracheotomie künstlich respirirenden Thier ist kein schwieriger Eingriff. Nach Spaltung der Haut und Galea in der Richtung der Pfeilnaht wird ein Temporalmuskel von seinem Ursprung dureh einen leicht bogenförmigen Schnitt mit dem Scalpell abgetrennt, das Periost mit dem Raspatorium abgelöst, und etwa $1 \mathrm{~cm}$ seitlich von der medianen 
Sagittalebene das Schädeldach vorsichtig in einem pfennigstückgrossen Bezirk entfernt. Nach Spaltung der Dura mater mit Schere und Pincette wird vorsichtig durch ein spatelartiges Instrument das Grosshirn in der Gegend des Corpus striatum oder des Pons von den tiefer gelegenen Abschnitten des C. N. S. durch einen queren, bis zur Basis cranii gehenden Schnitt getrennt. Eine Verletzung der venösen Sinus lässt sich umgehen. Eine stärkere Blutung ans den Gefässen der Hirnbasis ist in der Regel vermeidbar, wenn man dem Narkoseäther Chloruform zur Herabsetzung des Blutdrucks zusetzt.

Sofort nach der Decerebration muss die Narkose ausgeschaltet und das Thier durch Wärmekrüge oder Gummiwärmbeutel vor Abkühlung bewahrt werden. Die Herzaction leidet durch den Eingriff in der Regel nicht. An Stelle der künstlichen Athmung kann man nach etwa einer halben Stunde die Spontanathmung treten lassen, falls man nicht vorzieht, die erstere für die ganze Dauer des Versuches beizubehalten.

Setzen wir nun an einem auf diese Weise vorbehandelten Thier, dessen Harnblase womöglich leer ist, und dessen Magendarmeanal sich am besten in einem mittleren Füllungszustand befindet, einen einfachen mechanischen Reiz am Magen durch Kneifen mit den Fingern oder der Pincette, so erfolgt - auch dann, wenn jede Zerrung des Peritoneum und jede Bewegung des Thieres unterbleibt - eine sofortige Verstärkung der Uteruscontractionen. Ganz denselben Effect erhalten wir bei mechanischer Reizung der verschiedenen Abschnitte des Dünn- und Dickdarmes.

Weit stärker wurden die Uteruscontractionen, wenn chemische Reizmittel im Magen oder Darm zur Anwendung kamen: Glaubersalz, Eisenchlorid, Ferropyrin und besonders Argentum nitrieum in Lösungen zwischen $1 / 4$ und $2 \mathrm{pCt}$. und in Mengen von $3-10 \mathrm{ccm}$. Diese Flüssigkeiten werden durch die Schlundsonde in den Magen gegeben oder mit einer Spritze in die einzelnen Darmabschnitte injicirt. Es erfolgte allemal nach einigen Secunden eine Verstärkung der Uterusbewegungen (Taf. III, Fig. 3-5), und fast stets liess sich gleichzeitig am Darm eine verstärkte Peristaltik oder am Magen, als Zeichen wohl tetanischer Contractionen, eine plötzliche Verkleinerung und runzliche Beschaffenheit seiner Oberfläche erkennen. Fast immer aber war bei gleicher Reizstärke der Effect vom Colon auf den Uterus grösser als der vom lleum und die Wirkung vom Ileum aus stärker als vom Magen. Das hängt, wie 
später gezeigt werden soll, mit den Innervationsverhältnissen zusammen.

Zeigten diese Versuche eine innige Abhängigkeit der Bewegungen des Uterus von denen des Magendarmcanals, so liess sich doch der Einwand erheben, dass die angewandten mechanischen und chemischen Reize im lebenden Organismus nicht in Action treten. Weit grösseres Interesse beanspruchte daher die Frage, ob die physiologisch in Magendarmcanal wirksamen Reize von Einfluss auf die Uterusbewegungen sind.

Füllen wir in einer dritten Versuchsreihe den Magen oder irgend einen Darmabschnitt ziemlich schnell und prall mit lauwarmem Wasser, physiologischer Kochsalzlösung oder Milch, so folgt diesem Reiz eine Hemmung der Uterusbewegungen für die Dauer von mindestens 5-10 Minuten: Der Uterus, der vorher seine characteristischen regulären Pendelbewegungen ausführte, steht, ohne dass der Tonus sciner Musculatur wesentlich sinkt, still, der Uterushebel schreibt auf der Kymographiontrommel eine horizontale oder leicht absinkende Linie (Taf. IV, Fig. 6 a u. 6 b). Auch vom Colon aus ist die hemmende Wirkung auf den Uterus sehr deutlich zu erhalten; weniger gut von den einzelnen Dünndarmabschnitten aus. Bei ihnen ist der Dehnungseffect nur ein kurzdauernder; die injicirte Flüssigkeit verteilt sich im Dünndarm schnell nach beiden Richtungen hin, wodurch sehr bald eine Peristaltik angeregt wird, welche reflectorisch zu einer Verstärkung der Uteruscontractionen führt. Auf Ausdehnung des Magens oder irgend eines Darmabschnitts tritt also der Uterus in ein Ruhestadium ein. Das ist der experimentelle Beleg für die oben mitgetheilte Erfahrung, dass bei gefülltem Magendarmcanal die Wehenthätigkeit ungenügend ist.

Etwa 10 Minuten nach der Magendehnung beginnt der Uterus erst langsam, dann schneller und regulärer von Neuem seine Contractionen und zwar ungefäbr zur gleichen Zeit, in der am Duodenum und Jejunum eine beginnende Füllung, eine stärkere Blutgefässinjection und Peristaltik sichtbar wird. Es kann keinem Zweifel unterliegen, dass diese Uteruserregung von der gesteigerten Bewegung der oberen Darmabschnitte bezw. des Magens abhängt, und dass sensible Reize ätiologisch nicht in Frage kommen können. Beide treten aber in Action, wenn der leere Magen oder Darm durch die Schlundsonde oder eine Pravaz'sche Spritze mit ge- 


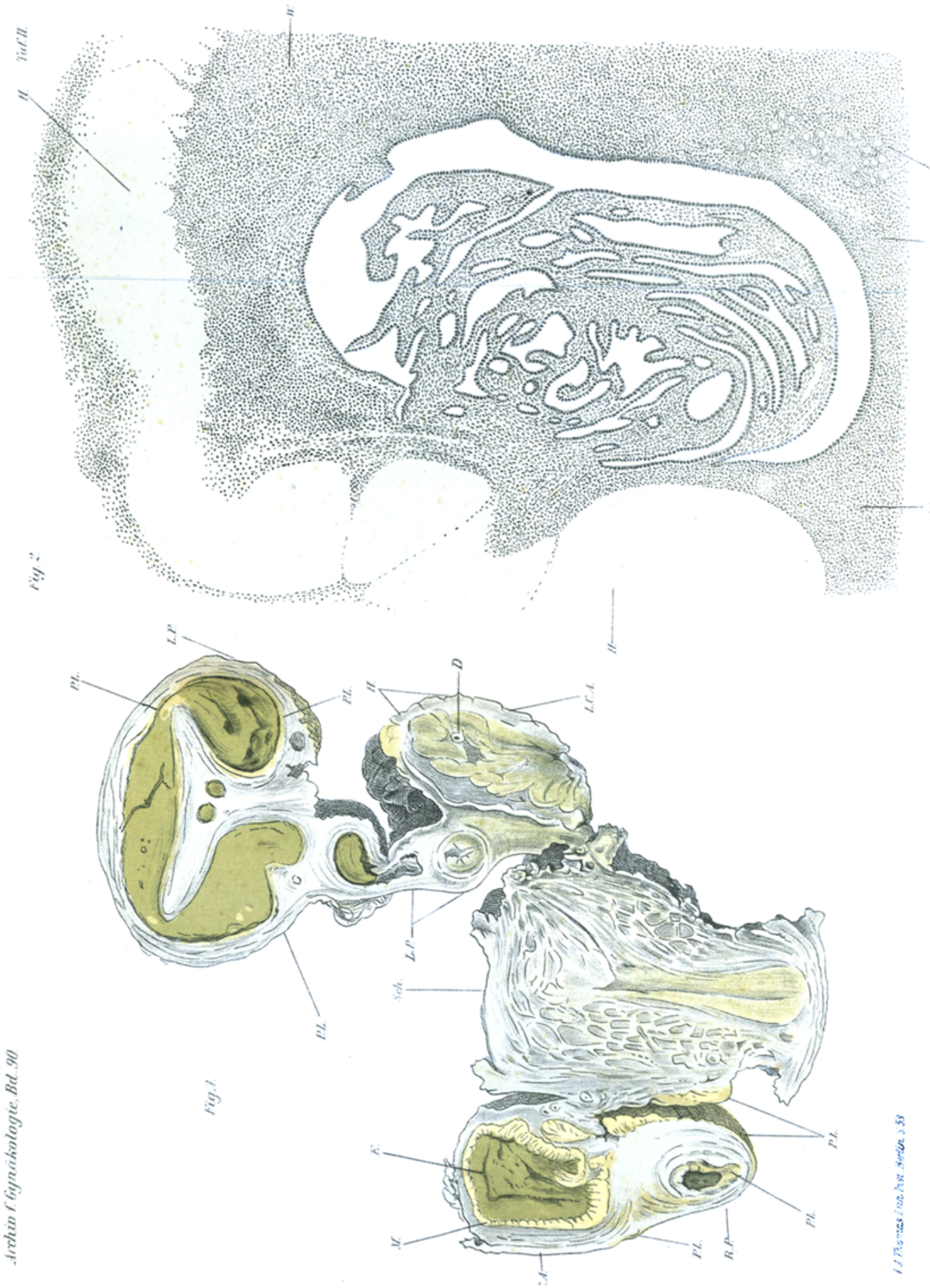


ringen Flüssigkeitsmengen $(20-30 \mathrm{ccm})$ gefüllt werden. Dann kommt es reflectorisch zu éiner Verstärkung der Uterusbewegungen.

Was mit indifferenten Flüssigkeiten erreicht wird, gelingt in noch besserer Weise mit den physiologischen Mitteln, die im Magen und Darm als Sekrete der Drüsen die Nahrung verdauen, z. B. mit der Salzsäure, sowie den Verdauungsproducten selbst, z. B. den Peptonen. Auch alle flüssigen Nahrungsmittel, die in kleinen Mengen dem Magen einverleibt werden und die Thätigkeit des Magendarmcanals anregen: z. B. Milch, Eiweisslösungen oder concentrirte Zuckerlösungen (Taf. IV, Fig. 7) wirken reflectorisch für längere Zeit erregend auf den Uterus ein.

Injicirt man in den Magen (Taf. V, Fig. 9a) oder in eine Dünndarmo- der Dickdarmschlinge 5-20 ccm einer $3-5$ proc. PeptonWitte-Lösung - nach 0 . Cohnheim (16) finden sich im Darm nach eiweissreicher Nahrung 38-40proc. Peptonlösungen - so beobachtet man mit blossem Auge eine Zunahme der Darmperistaltik und gleichzeitig eine beträchtliche Verstärkung der Uterusconträctionen. Diese letatere ist am intensivsten nach Injection des Peptons in den Dünndarm (Taf.V, Fig. 9 b), so dass man daraus, sowie aus der aussergewöhnlich lange anhaltenden uterinen Erregung auf. eine gleichzeitige Resorptionswirkung schliessen muss. Wissen wir doch aus der Physiologie der Verdaung, dass die Peptone weit mehr vom Dünndarm als vom Magen aus resorbirt werden, und aus früher von mir mitgetheilten Untersuchungen, dass auf intravenöse Injection von Peptonlösungen die Uterusbewegungen eine der Ergotin- und Adrenalinwirkung ähnliche Verstärkung erfahren.

Bringt man mit der Schlundsonde etwa 5-15 $\mathrm{ccm}$ einer 0,3 proc. Salzsäurelösung in den Magen - eine Concentration von 0,35 pCt. besitzt der menschliche Magensaft am Ende der Magenverdauung nach früheren Untersuchungen, eine solche von 0,44 bis 0,48 nach neueren Untersuchungen von F. Seiler (17) und Verhaegen (18) - so zeigt sofort auch der Uterus eine Verstärkung seiner Contractionen (6 Versuche). Aber dieser Effect geht bald vorüber, der Uterus kommt zur Ruhe. Und dieses, etwa 10 Min. anhaltende, Ruhestadium geht, wie die Abbildungen 8a u. 8 b (Taf. IV) zeigen, in eine etwa halbstündige Periode sehr lebhafter Contractionen über. Die erste kurzdauernde Erregung möchte ich als Effect der bei der Injection kaum zu umgehenden mechanischen Reizung des Schlundes und des Oesophagus, und als die Folge der chemischen Reizung sensibler Magennerven deuten. Die zweite Er- 


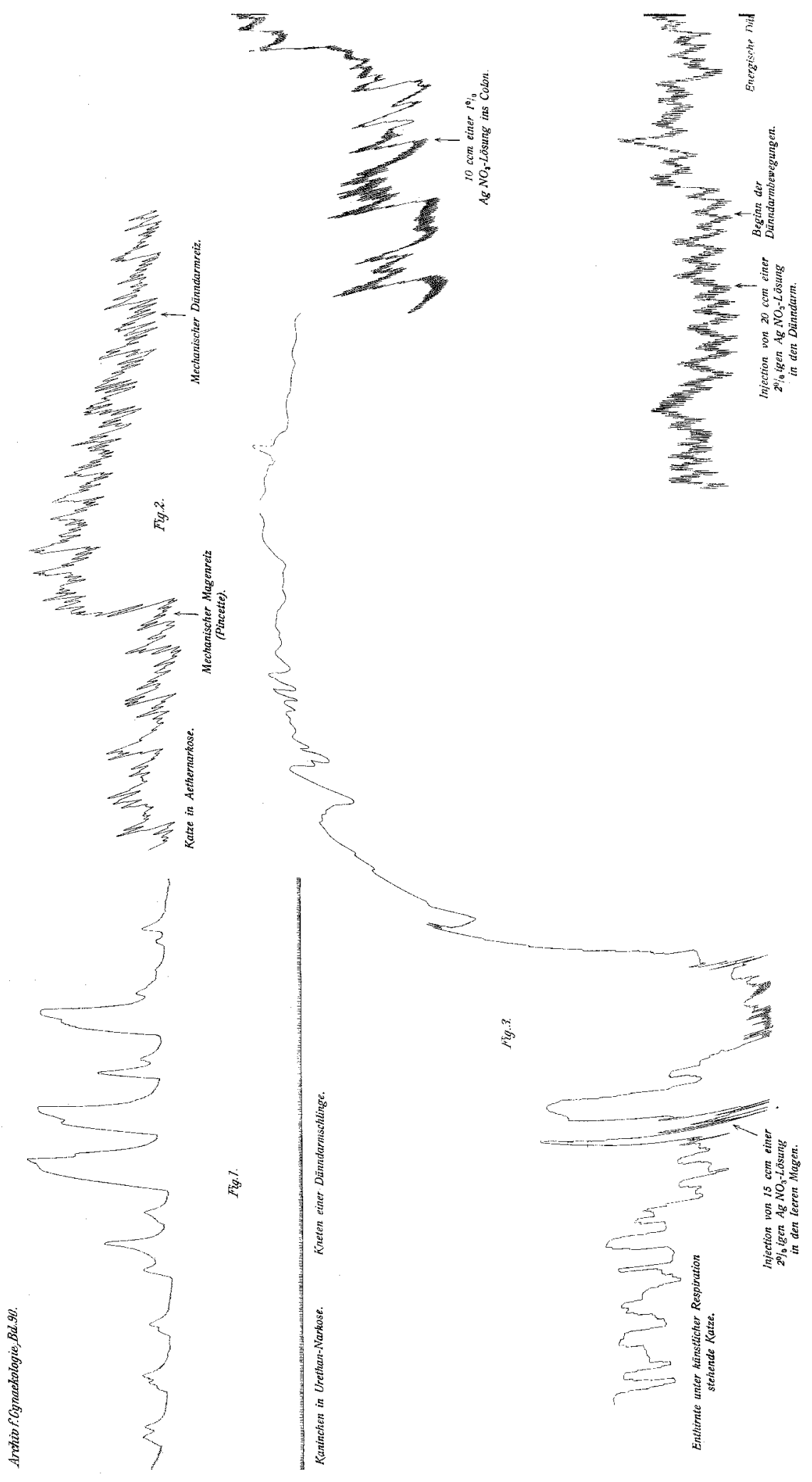




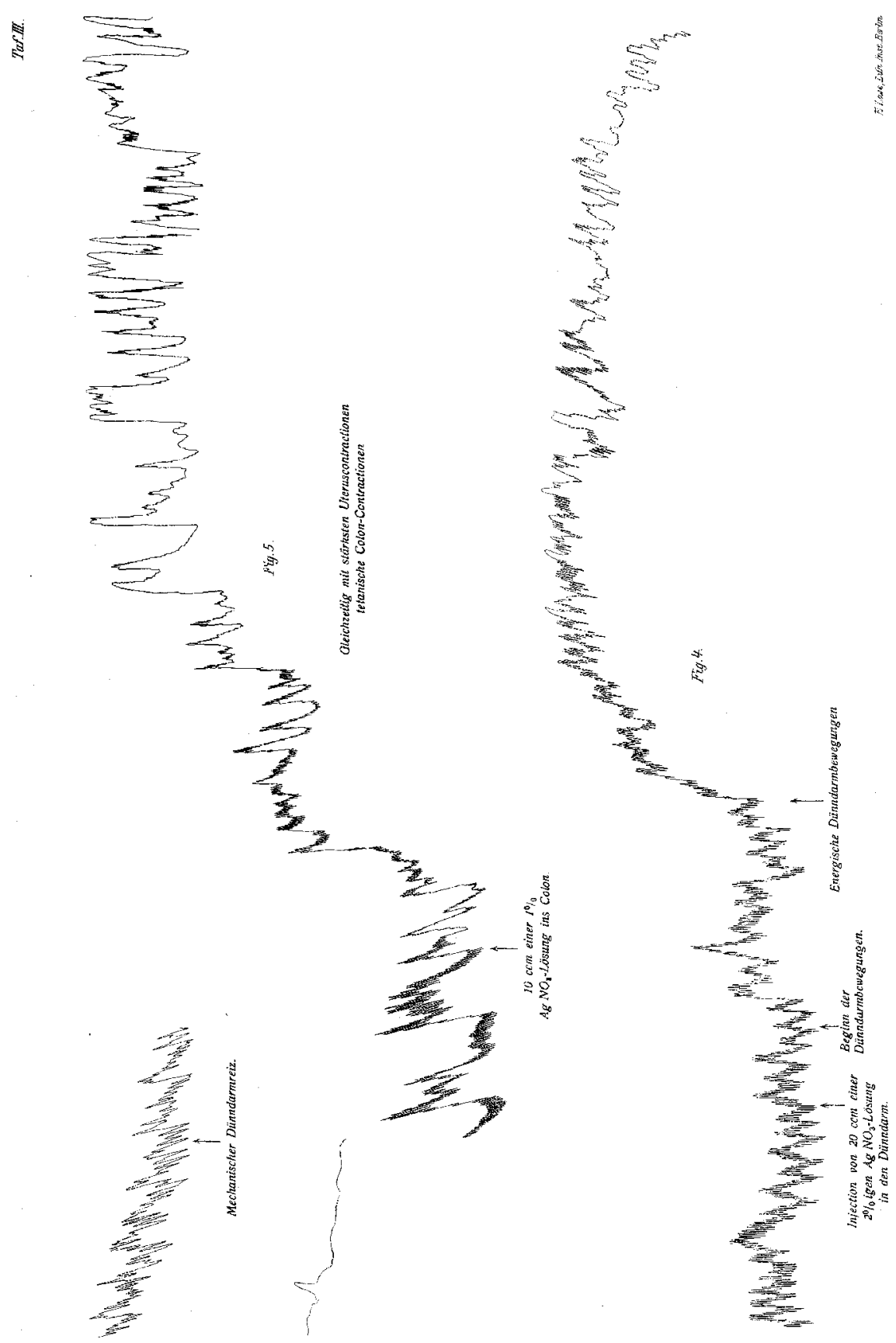




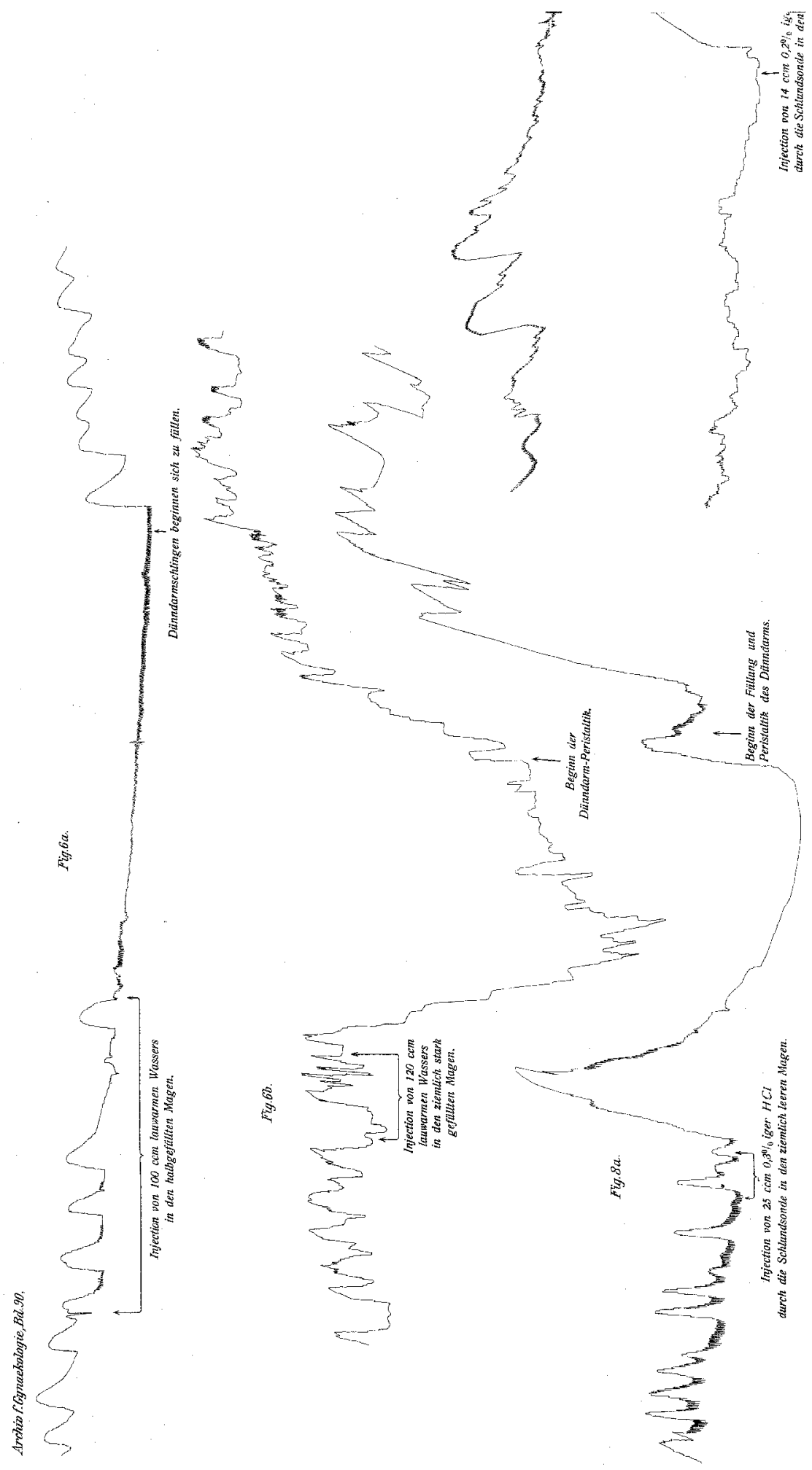


हैं

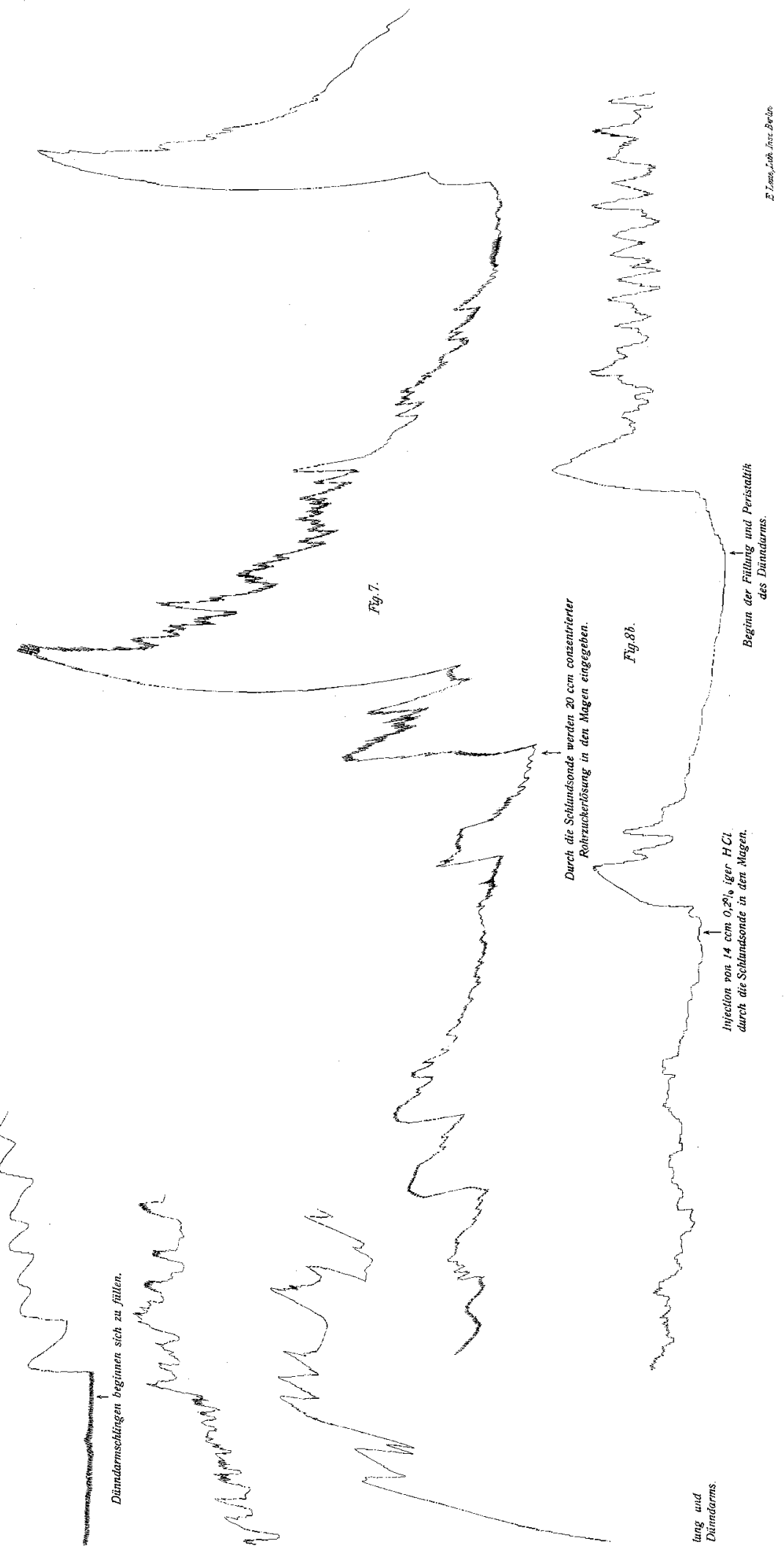


regung beginnt, wie man mit blossem Auge deutlich erkennen kann, in dem Augenblick, da die bis dahin ruhigen Dünndarmschlingen sich unter Zunahme der Gefässinjection und der Füllung vom Magen aus heftiger bewegen. Eine Ursache für die zwischen beiden Erregungsstadien liegende Ruhepause des Uterus kann ich nicht angeben.

Experimente, in denen Salzsäure, Peptone oder reichliche Flüssigkeitsmengen mit der Schlundsonde in den Magen gebracht werden, wurden auch noch in anderer Weise als oben beschrieben, ausgeführt: Die Thiere wurden in leichter Aethernarkose mit dem Rïcken auf ein Operationsbrett aufgebunden. Durch eine feine Oeffnung im Peritoneum parietale der vorderen Brustwand wurde ein mit einem Schreibhebel verbundener dünner Faden nahe der Uterushornspitze an das Lig. ovarii angelegt. Auch diese Versuchsanordnung ergab genau dieselben Resultate, so dass man sagen kann:

Die Uterusbewegungen stehen in innigen Beziehungen zum Magen-Darmcanal. Es giebthemmende und erregende Magen-Darmreize und ebensolche Uterusreflexe. Starke Füllung des Magens und aller Darmabschnitte versetzt den Uterus in einen voräbergehenden Ruhezustand. Alle mechanischen und chemischen Reize, die den Magendarmcanal von der Sehleimhaut oder der Serosa aus treffen, rufen theils durch Reizung sensibler MagenDarmerven, theils durch Anregung der Magen-Darmperistaltik eine Verstärkung der Uterusbewegungen hervor. Dass es sich hier nur um nervöse Reflexe vom Magen und Darm auf den Uterus handelt, kann keinem Zweifel unterliegen. Die Frage ist nur die: auf welchen Nervenbahnen spielt sich der Reflex ab?

Der Magen wird rom Vagus und Splanchnicus, der Dünndarm bis zur Valvula Bauhini vom Splanchnicus, das Colon im Wesentlichen vom Hypogastricus, ausserdem aber von Fasern des Pelvicus und Splanchnicus versorgt. Auf einem oder mehreren dieser Wege müssen die afferenten resp. sensiblen Reize vom Magen-Darmcanal einer Centralstelle - sei es dem Rückenmark oder den ausserhalb desselben gelegenen sympathischen Ganglien - zugeführt und von ihr auf motorischen Bahnen zum Uterus geleitet werden. Die genannten Nerven gehören ausnahmslos dem "autonomen System" Langley's (19) an, d. h. die vom Rückenmark entspringenden, Archiv für Gynäkologie Bd. 90 . H. I. 
mit einer gewissen Selbstständigkeit ausgestatteten Nerven gehen nicht direct zu dem von ihnen innervirten Organ, sondern enden in einem sympathischen Ganglion, von dem aus erst eine zweite Faser zum peripheren Organ hinzieht. Diese letztere wird als postganglionäre von der präganglionären, zwischen C. N.S. und peripherer Nervenzelle gelegenen Faser unterschieden.

Figur a. (Nach Langley).

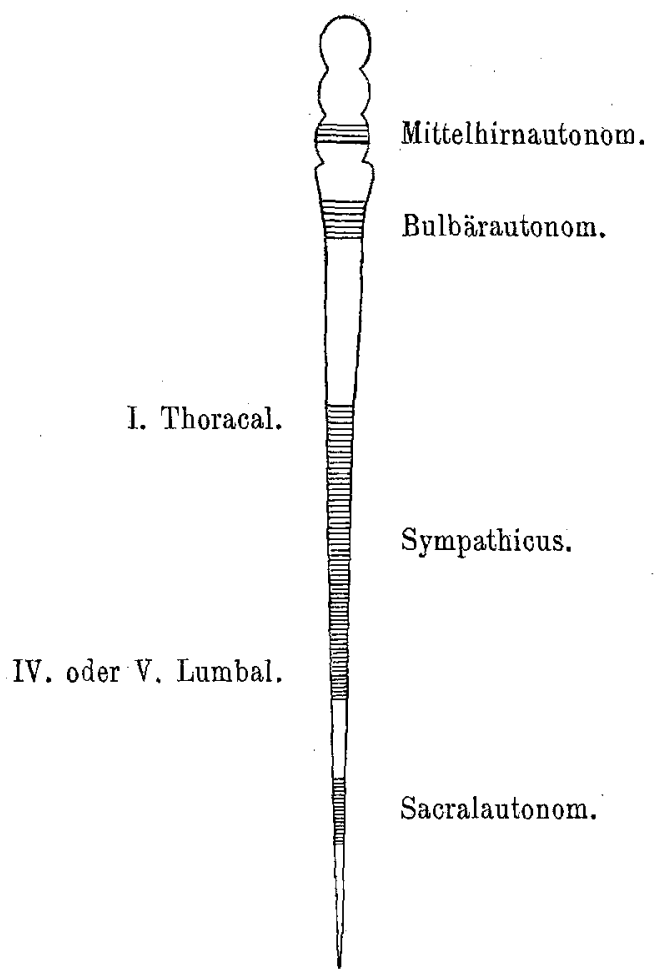

Dem autonomen Systeme (Fig. a) gehört der den ganzen Körper mit autonomen Fasern versorgende Sympathicus sowie das nur locale Gebiete innervirende cranial- und sacral-autonome System an. Die Fasern des Sympathicus verlassen dort, wo die Nerven für den Rumpf entspringen, zwischen dem 8. Brust- und dem 4. Lendensegment, die Vorderwurzeln des Rückenmarks, passiren die weissen Rami communicantes und den Grenzstrang und treten - soweit sie zur unteren Körperhälfte ziehen - in eines der prävertebralen Ganglien: Ganglion solare seu coeliacum, Ganglion mesentericum superius und inferius, Ganglion renale und 

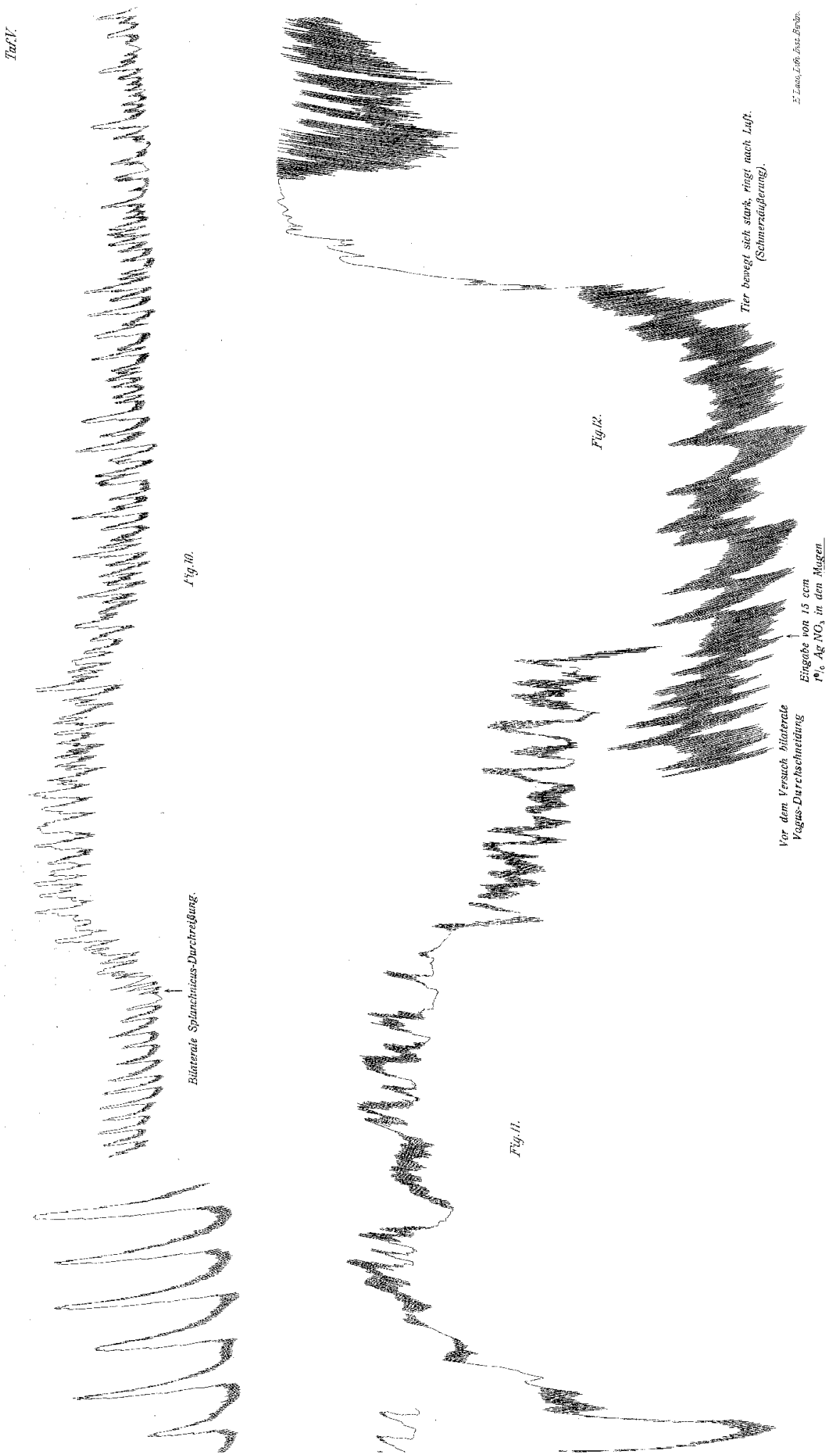


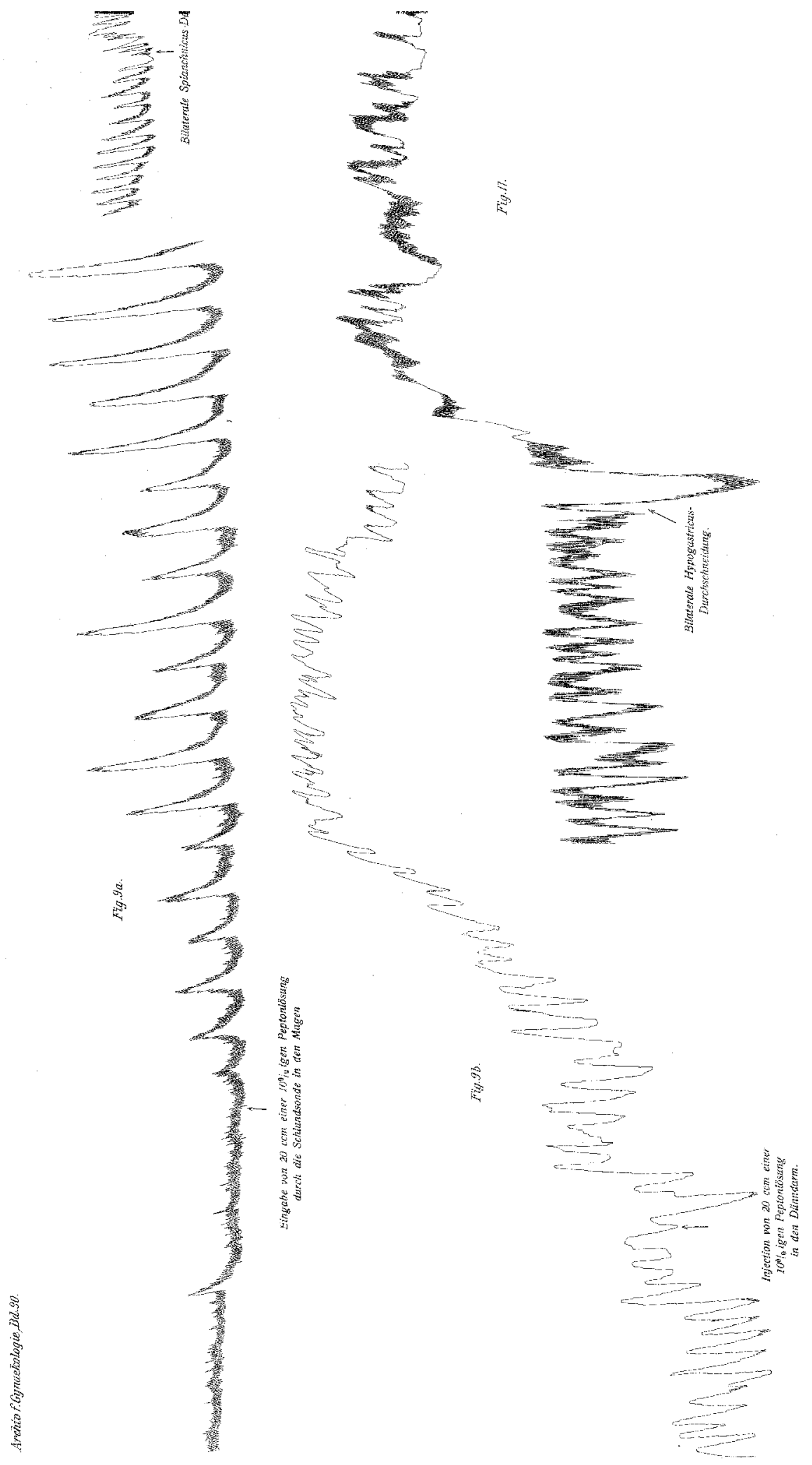


spermaticum ein, um dann im Splanchnicus, Hypogastricus und Spermaticus, sowie in engem Verband mit den Blutgefässen zu den peripheren Organen: Darmcanal, Niere, Blase und Ureteren und zu den Genitalien zu verlaufen. Dem cranial- bezw. bulbär-autonomen System gehört nach Langley der Vagus, dem sacral-autonomen System der Pelvicus an. Diese Verhälnisse giebt das Langleysche Schema in Fig. a wieder. Analog ist das Schema der sensiblen Innervation.

Was den Ursprung und die Topographie der für unsere weiteren Versuche wichtigen Nerven anbelangt, so entspringen die N. splanchnici bei der Katze rom 12. oder 13. Ganglion thoracicum bis herab zum 3. Lendenganglion des Grenzstrangs, beim Menschen vom 11. und 12. Brustganglion des Grenzstrangs (Broesicke), durchbohren lateral von der Aorta descendens thoracica die Pars vertebralis des $Z_{w}$ erchfells und gelangen vor der Aorta abdominalis zum Ganglion solare. Vorher theilt sich jeder Splanchnicus in 2 Aeste: der Ramus posterior, dem N. splanchnicus minor des Menschen entsprechend, läuft hinter der Nebenniere zum Plexus renalis; der Ramus anterior tritt in's Ganglion solare seu cocliacum ein. Von diesem verläuft, mit den gleichnamigen Arterien vereint, der N. coeliacus zum Magen, der N. mesentericus superior zum Ileum.

Der N. hypogastricus entspringt von dem an der Abgangsstelie der A. mesenterica inferior von der Aorta gelegenen Ganglion mesentericum inferius; welches bei der Katze nach LangleyAnderson vom 4.-6. Lumbalganglion des Grenzstrangs zuführende Aeste erhält. Der Nerv läuft prävertebral nach unten, theilt sich auf dem Promontorium in 2 Züge, zieht längs der hypogastrischen Blutgefässe, zwischen A. iliaca communis und Vorberg in's kleine Becken und sendet seine Zweige zum Frankenhäuser'schen Cervicalganglion, sowie direct zu Uterus, Rectum, oberen Theil der Vagina, Ureteren, Blase und Urethra. Im Einzelnen gestaltet sich die Innervation nach Frankenhäuser's (20) und besonders nach Langley's (21) ausgezeichneten Untersuchungen folgendermaassen:

Ein Nervenfaden des Hypogastricus verläuft vom unteren Mesenterialganglion dorsal nach unten als "accessorischer Hypogastricus", mehrere Nervenfäden helfen bei der Bildung des feinen, die Aorta umspinnenden Plexus aórticus und versorgen tiefer unten die Blutgefässe des kleinen Beckens. 1 Ast geht zur A. mesenterica inferior und damit zum Colon (Jumbale Colonnerven). 3 Aeste gehen zu den Ureteren; der erste entspringt dicht beim Ganglion 

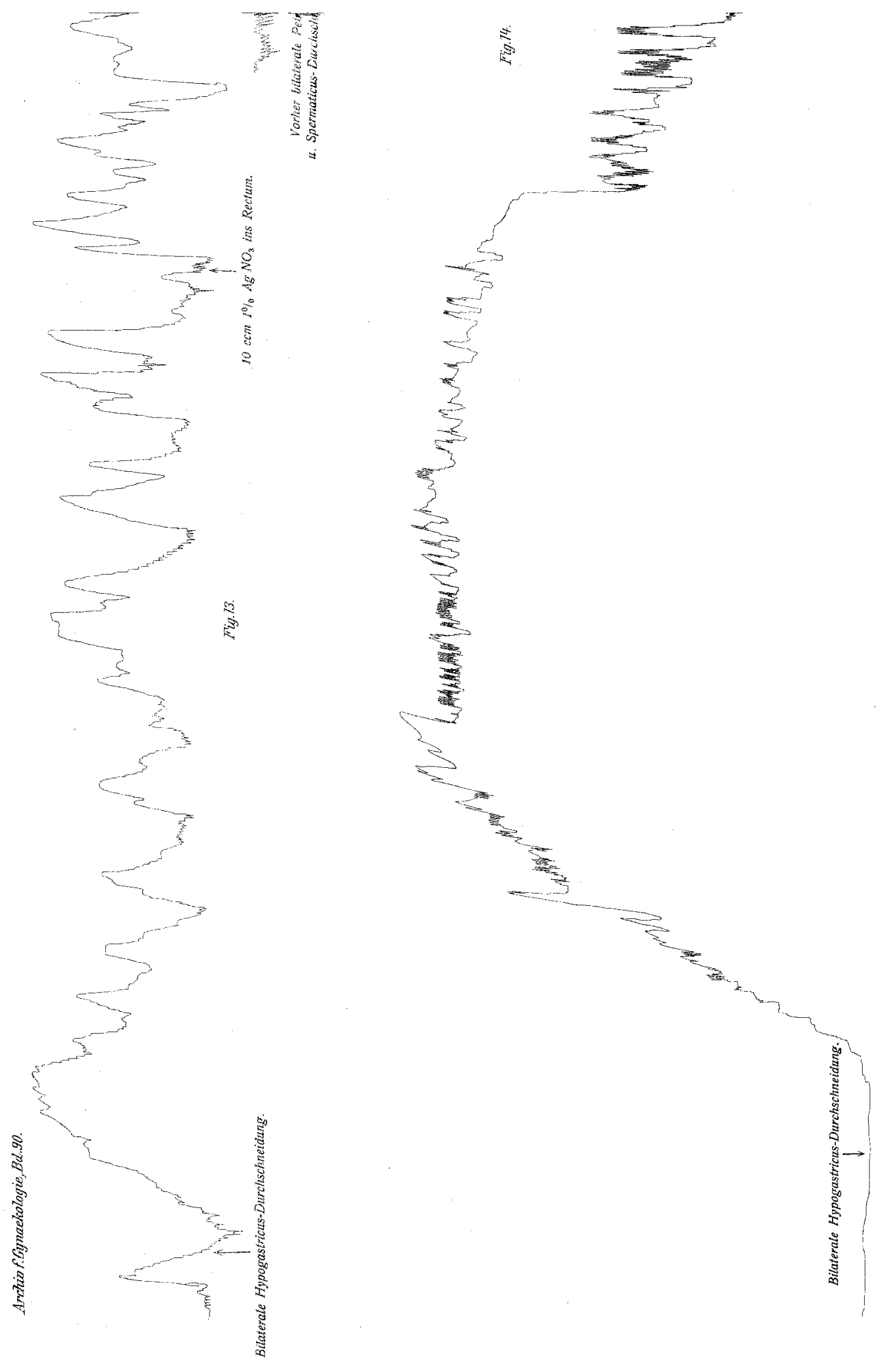
ลี

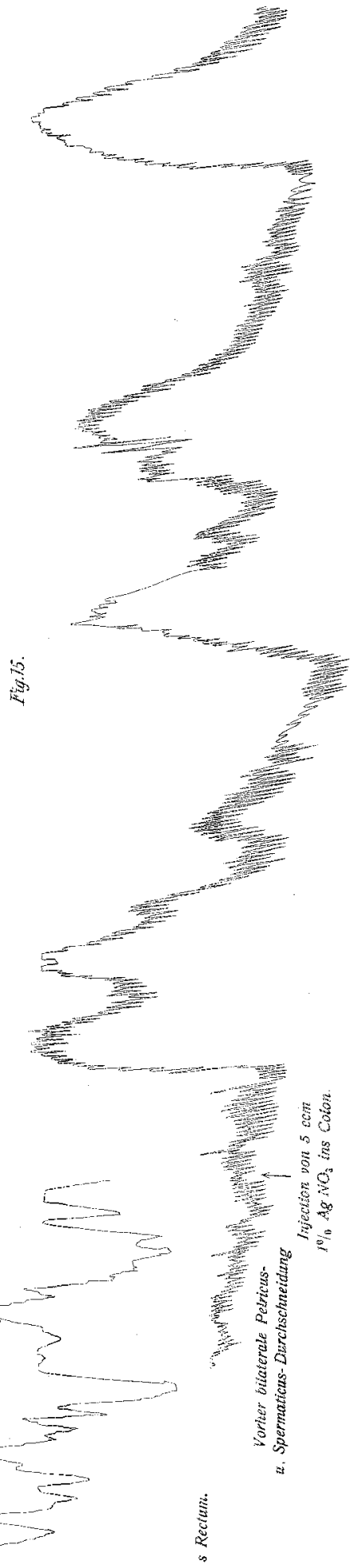

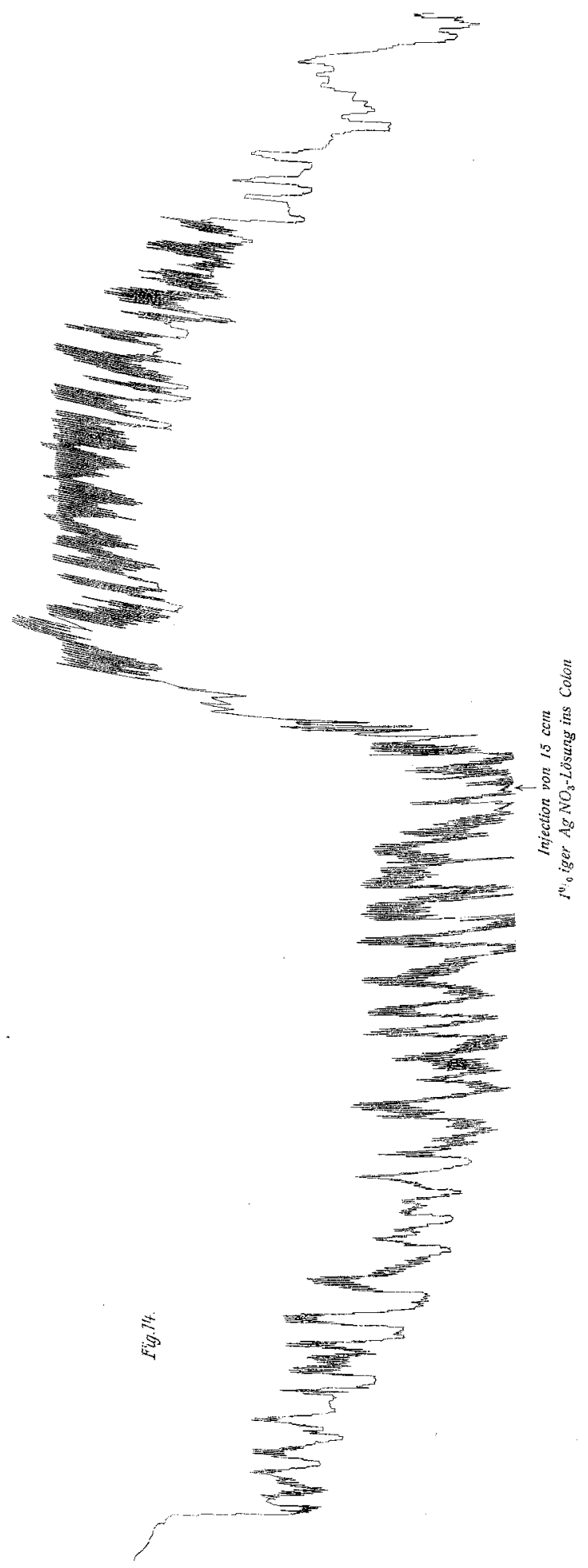


mesentericum superius, der zweite von der mittleren Partie des Nerven, der letzte nahe der Kreuzungsstelle des Hypogastricus mit dem Ureter, kurz vor der Theilung des Nerven in seine beiden Hauptstränge.

Bald nach dem Abgang dieses untersten Ureterastes sendet der noch vereinigte Hypogastricusstamm Zweige zur Basis der Blase in die Gegend des Uretereintritts, zur Urethra und zur Verbindung mit vesicalen Aesten des N. pelvicus. Entlang dieser Zweige liegen Gruppen von Nervenzellen und Ganglien [Langley (21)], welche mit den von de Lee (22), Frankenträuser und Ph. Jung (23) beschriebenen äusseren und inneren Vesicalganglien identisch zu sein scheinen. Die ersteren finden sich an der Aussenseite des Ureters, unmittelbar vor seinem Eintritt in die Blase, die letzteren liegen zwisehen der inneren Seite des Ureters und der Cervix uteri. Beide Gangliengruppen sind durch einen den Ureter kreuzenden Nervenast verbunden und stehen mit dem mehr dorsalwärts gelegenen grösseren Frankenhäuser'schen Cervicalganglion in directer Verbindung (Frankenhäuser).

Nahe dem oberen Ende des Rectums, an der dorso-lateralen Wand desselben, theilt sich der Hypogastricusstamm in einen dorsalen und ventralen Zweig. Der Ramus dorsalis giebt Zweige zum Pelvicus ab und tritt beim Kaninchen in das Frankenhäuser'sche Cervicalganglion ein, das nach Langley aber keine Beziehungen zum Uterus hat, nur Aeste zum Colon und zur Blase schickt und auch beim Männchen existirt. Die Verbindungen zwischen diesem Ganglion und dem vorderen Zweig des N. pelvicus werden von Frankenhäuser und Krause als Hämorrhoidalplexus bezeichnet. In dem dorsalen Zweig des Hypogastricus steigen - wenigstens beim Kaninchen - zahlreiche Fasern von den 1.-4. Sacralwurzeln anfwärts, wie Langley's Degenerationsversuche lehren. Er fand nach Durchtrennung der Sacralwurzeln 25 degenerirte und 40 gesunde Nervenfasern im Hypogastricus unmittelbar über seiner Theilung.

Die ventrale Partie des Hypogastricus giebt einen $\Lambda$ st direct. zum Ureter ab, hat Gruppen von Nervenzellen an ihren Aesten und tritt in den Plexus von Gangliengruppen ein, der an der dorso-lateralen Wand der Cervix und oberen Vagina gelegen ist (Langley) und der beim Menschen Nervenzweige vom 5. Lumbalganglion und dem 1.-3. Sacralganglion des sympathischen Grenzstrangs aufnimmt (Frankenhäuser). Die von diesem Franken- 


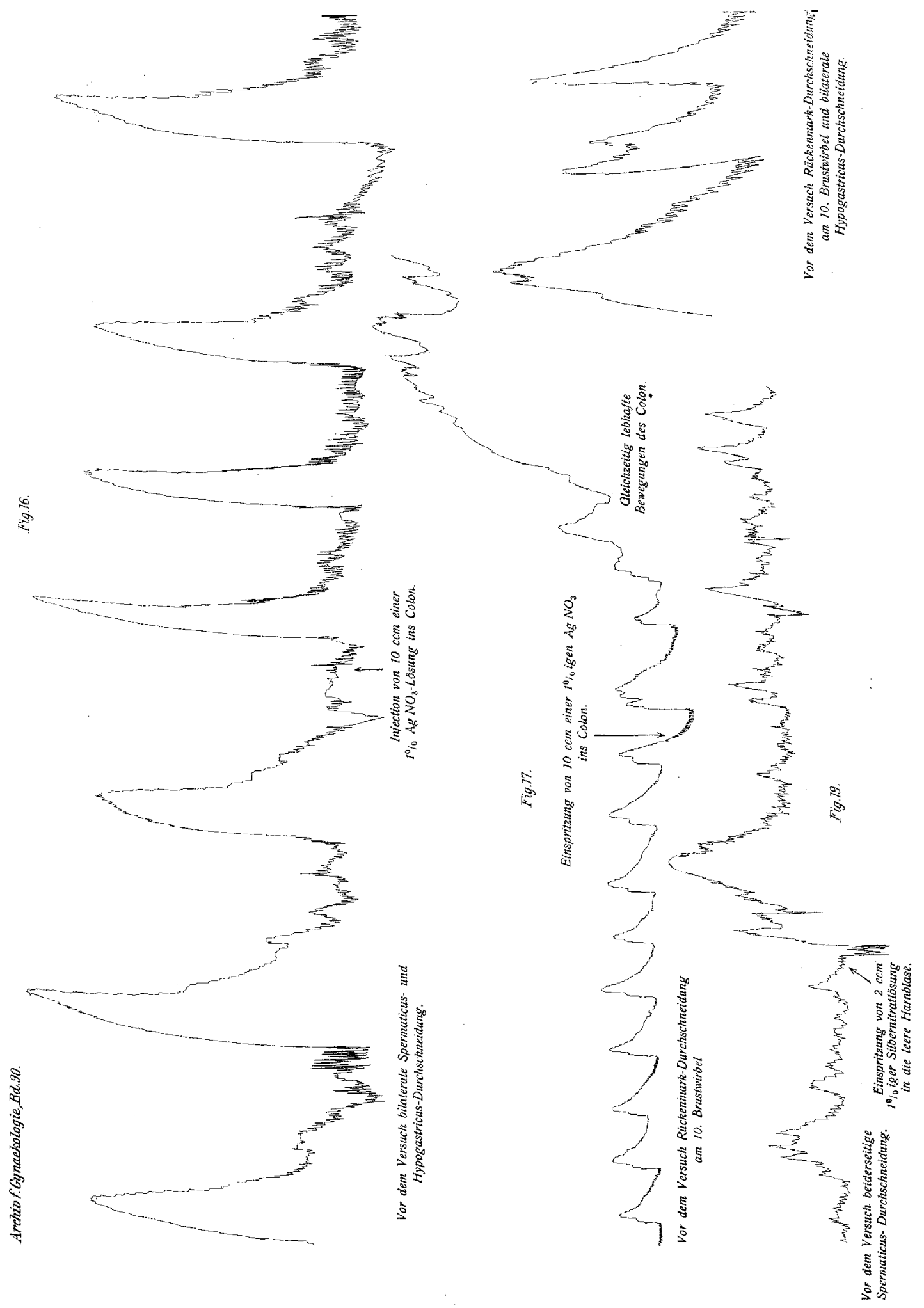


8
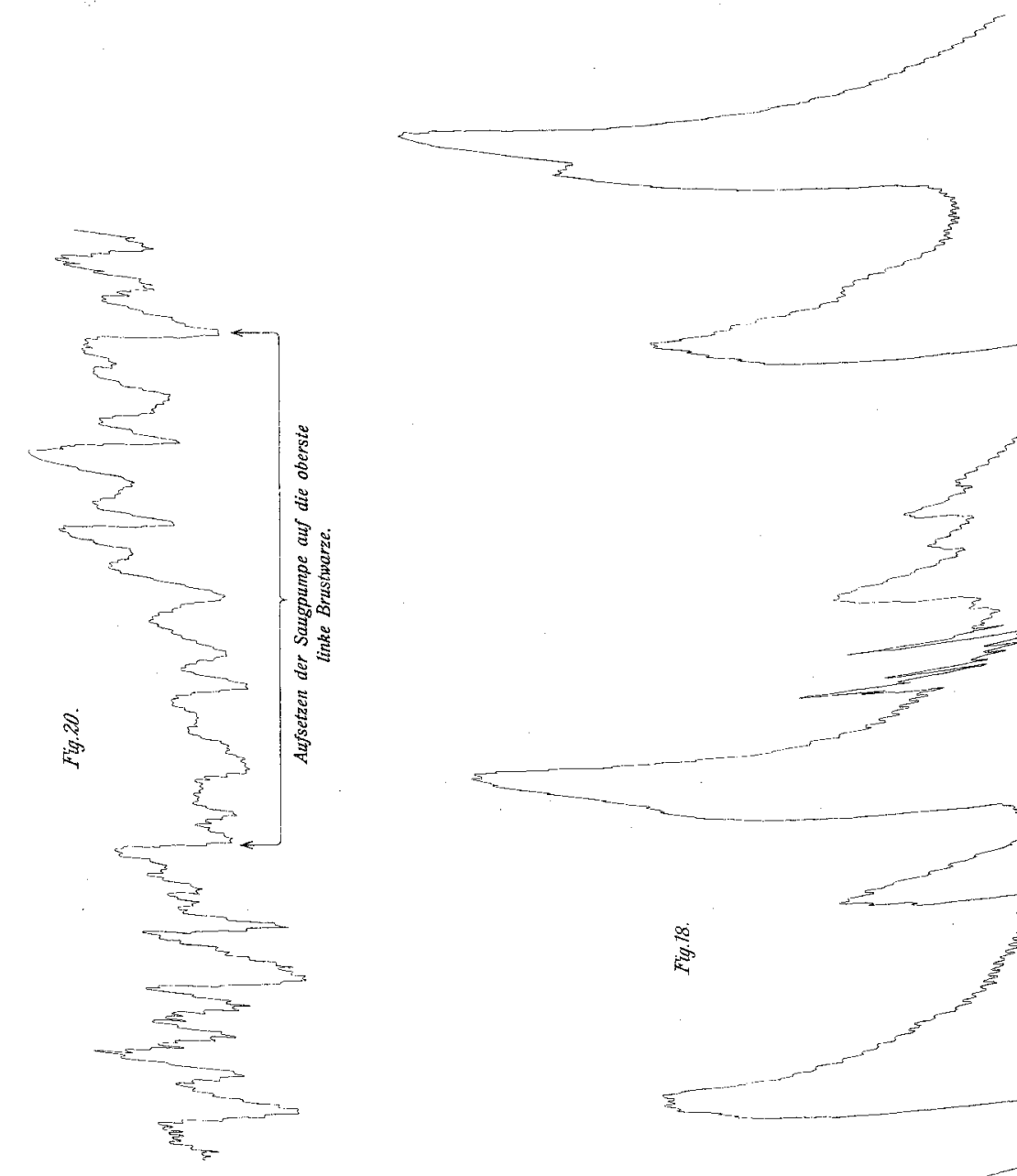
häuser'schen Ganglion cervicale abgehenden Aeste versorgen nach

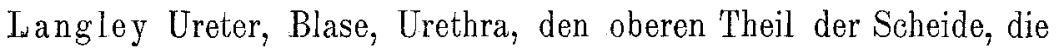
Cervix und die unteren zwei Drittel des Uterushorns, nach Frankenhäuser den ganzen Uterus und den oberen. Theil der Vagina. Sie verlieren sich nach Langley zuletzt im Plexus vaginalis und vulvaris.

Der Beckennerv entspringt jederseits aus dem 2.-4., im Wesentlichen aus dem 2. Sacralnerven. Von den bejden Hauptästen tritt jeder in ein grösseres Ganglion ein. Von dem am meisten hinten, nahe dem Rectum gelegenen I. Beckenganglion verlaufen Nervenfasern nach 3 Richtungen: Die posterioren Fasern ziehen zum Colon (sacrale Colonnerven Langley's), zum Rectum und zum M. recto-coccygeus. Die postero-medianen Stränge - die Frankenhäuser als recto-vaginale, Langley aber als recto-genitale Fasern bezeichnet, da sie in gleicher Weise bei beiden Geschlechtern vorkommen - wenden sich zum Rectum, zur Vulva, zum N. dorsalis clitoridis und helfen bei der Bildung des Plexus vaginalis, urethralis und vulvaris. Die anterioren oder urethro-vesicalen Stränge innerviren die Urethra und die an sie grenzende-Blasenpartie. Der 2. Hauptast des Pelvicus tritt in's 2. Beckenganglion ein, das einen Ast zur Urethra und unteren Vagina, einen anderen zum Ganglion uterinum und aufstejgende Fasern bis zum Hypogastricusstamm sendet.

Der Pelvicus innervirt nach Langley den Uterus weder mit efferenten noch mit afferenten Fasern. Auch den von Frankenhäuser beschriebenen N. atero-sacralis, der dem III. Sacralnerven entstammen und zu den Uterushörnern ziehen soll, hat Langley nicht gefunden. Waren nach Durchschneidung des Pelvicus alle seine Fasern degenerirt, so liessen sich im Mesometrium und im Uterus keine degenerirten Fasern nachweisen. Im Gegensatz zu dieser Beschreibung des Physiologen Langley treten nach Frankenhäuser's rein anatomischer Präparation zahlreiche Nervenfäden des Pelvicus mit dem Cervicalganglion und so mit dem Uterus in Verbindung.

Die Fundusgegend des menschlichen Uterus, die Hornspitze des Uterus bicornis der Thiere werden gleich Tuben und Ovarien durch die im oberen Theil des Lig. latum, der Ala vespertilionis mit den Spermaticalgefässen vereinten $\mathrm{Nn}$. spermatici versorgt. Diese entspringen von den als Genital-, Ovarial- oder Spermaticalganglien bezeichneten Ganglien, welche, als Theile der prävertebralen Gangliengruppen, lateral von der A. mesenterica superior, 
beim Thier an der Seite des 4. Lumbalwirbels, unterhalb der Nierengefässe und der Renalganglien, übereinander gelagert sind. So viel über die anatomischen Verhältnisse der den MagenDarmcanal und die inneren Genitalien versorgenden Nerven. Die nun zu lösende Aufgabe war, $a b$ und in welcher Weise nach isolirter oder verschiedenartig combinirter Durchschneidung der genannten Nerven sowie des Rückenmarks die oben besprochenen hemmenden und erregenden Reflexe vom Magen und Darm auf den Uterus eine Veränderung erfahren. Bei diesen theilweise recht schwierigen Versuchen wurden die Nerven in folgender Weise aufgesucht and durchtrennt:

Die Isolirung des Vagus von der Carotis geschah im Anschluss an die Tracheotomie. Der Nerv wurde zur späteren. Durchschneidung in einer Fadenschlinge festgehalten.

Der Splanchnicus wurde von der Stelle, an der er zwischen Zwerchfellpfeiler und M. ileopsoas in die Bauchböhle eintritt, bis. zum Ganglion coeliacum isolirt and dicht unter dem Diaphragma. in eine Fadenschlinge gelegt. Die Präparation auf der rechten Seite ist etwas schwieriger als auf der linken; erst wenn die Leber vorsichtig nach oben medianwärts, die Nebenniere nach rechts gedrängt ist, lässt sich der rechte Splanchnicus nach Durchtrennung des den rechten Leberlappen mit der, rechten Niere verbindenden Ligaments deutlich sichtbar machen und bis zum Zwerchfelldurchtritt verfolgen. Die beiden Nerven werden entweder im Beginn des Versuchs durchschnitten oder im Verlaufe des Experiments bei dem bereits im Kochsalzbad befindlichen Thiere durch kräftigen plötzlichen Zug an der Ligatur durchrissen, da im letzteren Fall bei der hohen Lage der Nerven unter der Kuppel des Zwerehfells eine scharfe Durchtrennung nicht möglich ist.

Eine Durchschneidung während des Versuchs gelang nur bei den N. hypogastrici. Diese lassen sich, wenn man durch Emporheben des Rectums das Mesorectum entfaltet, als zwei parallel der Wirbelsäule vom Ganglion mesentericum inferius caudalwärts ziehende Stränge leicht erkennen [R. Magnus (25)]. Es ist vortheilhaft, auch die hypogastrischen Nerven provisorisch in eine Fadenschlinge zu legen, um während des Experiments durch Zug an ihr die Durchschneidung der Nerven zu erleichtern. Sie geschah stets nahe beim unteren Mesenterialganglion.

Die Sacralwurzeln wurden vor den Foramina sacralia anteriora vor dem Versuch durchschnitten. Den Pelvicus erreicht 
man entweder auf directem Weg vor und unterhalb der Kreazhüftfuge nach Spaltung des hinteren Blattes des Lig. latum, oder indem man längs des Hypogastricus in die Tiefe des Beckens erst nach abwärts, dann nach hinten aussen gegen die Beckenwand zu vordringt. Manchmal - besonders bei blutreichen Genitalien gravider und puerperaler Thiere - gelang die Aufsuchung der Pelvici nicht, wie die nach dem Versuch vorgenommene Section zeigte. Die Ergebnisse solcher Versuche wurden dann natürlich nicht in Rechnung gezogen.

Eine isolirte Präparation des N. spermaticus ist bei Katze und Kaninchen nur sehr schwer und unsicher auszuführen. Der Nerv ist zu dünn und von den vielen, die Spermaticalgefässe begleitenden Lymphwegen kaum zu trennen. Ich ging daher so vor, dass ich den oberen Theil des Lig. Jatum mit allen Gefässen und Nerven zwischen zwei Ligaturen mit der Scheere durchschnitt.

Jede Nervendurchschneidung war von Einfluss auf die Bewegungen des Uterus. Auf die Durchtrennung der Vagi antwortete der Uterus (in 5 von 7 Versuchen) mit einer kurz dauernden Hemmung der Contractionen. Ausnahmsweise geht dieser eine schnell verschwindende Erregung, wohl der Effect der mechanischen Reizung sensibler, in der Umgebung des Vagus gelegener Nervenfasern voraus. Ich vermuthe, dass die Hemmung nicht oder nicht nur als Reflexwirkung auf die motorischen Uterusnerven aufufassen ist, sondern auf die durch Vagusreizung bekanntlich erfolgende Hemmungswirkung am Herzen, oder auf vorübergehenden Circulationsstillstand $\mathrm{zu}$ beziehen ist. Schmerzäusserungen waren bei Vagusdurehsehneidung kaum wahrnehmbar.

Wurden die Splanchnici oder Hypogastrici oder Pelvici (Taf. V, Fig. 10 u. 11) durchschnitten oder durchrissen, so erfolgte eine langdauernde Verstärkung der Uterusbewegungen - nur zwei unter zahllosen Versuchen machten eine Ausnahme. Gleichzeitig bäumte sich die Katze, warf den Kopf hin und her, öffnete das Maul, streckte krampfhaft und oft rhythmisch die Zunge hervor kurz, sie machte lebhafte Abwehrbewegungen, die zweifellos als Schmerzäusserungen anzusehen sind, wenngleich diese nicht in der Grosshirnrinde ihren Centralsitz haben können. Denn das Grosshirn war ja bei unserer Versuchsanordnung von den übrigen Centralorganen isolirt. Am lebhaftesten waren die Schmerzäusserungen bei der Splanchnicusdurehschneidung.

Es ergiebt sich demach die sehr bedeutsame That- 
sache, dass die sympathischen Nerven, im Speciellen der Splanchnicus und Hypogastricus, sowie die Sacralwurzeln bezw. der Pelvicus neben den - wenigstens in den beiden erstgenannten Nerven - längst nachgewiesenen motorischen Fasern auch afferente oder receptorische, und zwar sensible Fasern besitzen. Der receptorische Charakter ist dadurch bewiesen, dass auf blosse Splanchnicusdurchschneidung Uteruserregung erfolgt und auf Magen-Dünndarmreize nach erfolgter Splanchnicusausschaltung die zu erwartende Uteruserregung fast ausbleibt. Die Anwesenheit sensibler Fasern ist durch die Schmerzäusserungen des Thieres nach der Nervendurchschneidung einwandfrei nachgewiesen. Ich kam zu diesem wichtigen Resultat lange bevor ich von den Langley'schen Angaben über den Gehalt des Sympathicus und des sacral-autonomen Systems an sensiblen Fasern durch die Güte von Herrn Professor Magnus Kenntniss erhalten hatte. Auch ist mein Weg ein ganz anderer, als der, den Langley-Anderson (26 u. 27) eingeschlagen haben. Nach diesen Autoren sind sowohl im Splanchnicus, wie im Hypogastricus 1/10, im Pelvicus sogar 1/3 aller Fasern sensibel. Sehmerzäusserungen des Thieres bei der Durchtrennung der Sacralnerven wurden übrigens lange vor mir und vor Langley schon von Rein beobachtet.

Auch die Spermaticalnerven enthalten, als dem sympathischen Nervensystem angehörig, zweifellos sensible Fasern, denn bei ihrer Durchschneidung sind Schmerzäusserungen wahrzunehmen. Der receptorische Charakter einzelner Spermaticalnervenfasern, erkennbar an der Uteruserregung bei der Nervendurchschneidung, kann nur auf Grund eines einzigen Falles behauptet werden, da die isolirte Spermaticusdurchschneidung bei kleinen Thieren aus den angegebenen Gründen kaum gelingt.

Die Frage, ob die allgemeine, in Bewegungen des Thieres sich offenbarende Erregung und die locale Erregung des Uterus Coëffecte der Reizung sensibler Nervenfasern sind, oder ob die uterine Wirkung die Folge von allgemeinen Bewegungen des Thieres ist, möchte ich in folgender Weise beantworten: Ein reflectorischmotorischer Effect auf den Uterus kann lediglich durch Reizung sensibler Nervenfasern erfolgen; er kann aber auch - wie ich früher schon nachwies - durch Bewegungen des Thieres hervorgerufen werden und - was hier bei der blossen Nervendurchschneidung zwar nicht in Frage kommt - durch Bewegungen ein- 
zelner Systeme glatter Muskulatur des Darmes oder der Blase. Es ist klar, dass eine Summation von 2 oder 3 dieser Factoren reflectorisch auch in der Intensität der Uteruserregung zum Ausdruck kommen muss.

Wie verhalten sich nun die Reflexe vom MagenDarmeanal auf den Uterus nach Durchtrennung der verschiedenen Nervenpaare?

Mechanische oder chemische Magen-Darmreize führten nach Durchschneidung der Vagi zu einer Verstärkung der Uteruscontractionen - ganz wie beim Thier mit intactem Nervensystem (Taf. $V$, Fig. 12). Daraus folgt, dass der afferente Abschnitt der Reflexbahn vom Magen oder Darm nicht durch den Vagus seinen Weg nimmt.

Wurden nach Abklingen der auf Splanchnicusdurchschneidung folgenden Darmhyperämie und Uteruserregung chemische Reize im Magen-Darmcanal angewendet, so ergaben sich folgende Resultate: Magenreize hatten nur noch äusserst schwache und kurz dauernde Wirkung auf den Uterus. Vom Ileum aus wurde in 4 Versuchen kein Effect, in je 2 Versuchen Erregung oder Hemmung der Uterusbewegungen erzielt. Silbernitratlösung, in das Colon injicirt, hatte stets ( 6 Versuche) eine intensive und sehr langanhaltende Verstärkung der Uteruscontractionen zur Folge. Vom Magen und Dünndarm aus lassen sich demnach nach Splanchnicusdurchschneidung nur noch äusserst schwache und flüchtige Reflexe, vom Colon aus noch sehr starke und andauernde Reflexe erhalten. Daraus folgt der receptorische Charakter des Splanchnicus für den Magen und Dünndarm, oder anders formulirt: Die receptorischen Fasern vom Magen verlaufen wohl ausschliesslich, vom Ileum aus grossentheils im Nervus splanchnicus, während diejenigen des Colon auf einem andern Weg: auf dem des Hypogastricus oder Pelvicus zu einem Centralorgan, dem Reflexcentrum hinziehen.

$0 b$ eine dieser beiden oder eine andere Nervenverbindung die Colon-Uterus-Reflexe vermittelt, sollte durch folgende Versuche festgestellt werden: Nach Durchschneidung der Pelvici waren noch starke Reflexe nachweisbar. Wurden die Hypogastrici durchtrennt oder wurde das Ganglion mesentericum inferius exstirpirt, so liess sich nur noch ein schwacher Effect auf den Uterus erhalten (Fig. 13, Taf. VI); nur in 2 von 9 Versuchen war die Wirkung stark (Fig. 14, Taf. VI). Auf combinirte Hypogastricus-Pelricus- oder Hypogastricus-Splanchnicus- oder Hypogastricus-Spermaticus - Aus- 
schaltung hatten Colonreize nur noch minimale, in manohen Fällen keine Wirkung auf den Uterus. So zeigt Fig. 16 (Taf. VII), wie der Rhythmus der Uterusbewegungen sich gegen früher nicht im geringsten ändert, obwohl nach gleichzeitiger Durchschneidung der hypogastrischen und spermaticalen Nerven das Colon auf injicirtes Silbernitrat sich so heftig bewegte, dass Kothmassen aus dem After gleichsam herausgestossen wurden und Gasblasen fort und fort aus dem Darm in die das Thier enthaltende Kochsalzflüssigkeit übertraten.

Es muss aus diesen Versuchen geschlossen werden, dass die Mehrahl der afferenten wie efferenten motorischen Fasern vom Colon durch den Hypogastricus zum Uterus gehen, wenn auch noch andere Verbindungen zwischen beiden Organen - sei es constant oder als Varianten - existiren. Ich komme auf diese Fasern, die im Einzelnen bei dem labyrinthartig complicirten Verlauf nicht ausfindig gemacht werden können, im Anschluss an Langley's Untersuchungen nachher zu sprechen.

Wird im Magen oder Dünndarm nach vorheriger HypogastricusDurchschneidung ein mechanischer oder chemischer Reiz angewendet, so wirkt dieser noch erregend auf den Uterus ein, wenn auch schwächer als bei intacten Nerven. Der wesentliche Motor des Uterus, der Hypogastricus, ist eben entfernt. Der Reflexbogen muss in diesem Fall vom Splanchnicus zum Spermaticus verlaufen. Das in Anspruch genommene Reflexcentrum dürfte in einem der oberen prävertebralen Ganglien, d. h. im Ganglion solare, mesentericum superius, renale oder ovaricum seu spermaticum zu suchen sein.

Nach Durchschneidung des $N$. spermaticus hat Silbernitratlösung, in den Magen, das Ileum oder Colon injicirt, genau denselben erregenden Einfluss auf die motorischen Functionen des Uterus wie beim intacten Thier, woraus geschlossen werden muss, dass der centrifugale Schenkel des Reflexbogens nicht oder wenigstens nicht allein durch den Spermaticus verläuft.

Werden nach Verschwinden der auf Durchschneidung der Sacralwurzeln folgenden Uterushemmung im Magen oder Darm chemische Reize angebracht, so ist der erregende Effect auf den Uterus gering. Werden lediglich die N. pelvici durchschnitten, so ist der motorische Effect weit stärker. Die erstgenannte Erscheinung möchte ich durch Shockwirkung erklären.

Was die Reflexe nach combinirten Nervendurchschneidungen anlangt, so wurde die uterine Wirkung von Colonreizen nach der vereinigten Pelvicus-Hypogastrieus-, Splanchnicus-Hy pogastricus- 
und Spermaticus-Hypogastricus-Ausschaltung bereits besprochen. Auch vom Magen und Ileum aus sind nach combinirter PelvicusHypogastricus- oder Splanchnicus-Pelvicus- oder SplanchnicusSpermaticus-Durchschneidung nur noch ganz minimale Reflexe auf den Uterus zu erhalten; sie bleiben ganz aus nach Durchtrennung der Splanchnici-Hypogastrici oder der Hypogastrici-Spermatici. Während also die isolirte Durchschneidung des Hypogastricus, des wichtigsten motorischen Nerven des Uterus, diesen letzteren nur schwächt, vermag die Ausschaltung der Hypogastrici im Verein mit einem der anderen beiden Nervenpaare: Splanchnicus oder Spermaticus den Uterus für Reflexe vom Magendarmcanal aus fast oder vollkommen unzugänglich zu machen. Im einen Fall fehlt die afferente receptorische Bahn: der Splanchnicus, im anderen Fall der zweite motorische Nerv des Uterus: der Spermaticus.

Nach diesen Untersuchungen dürfen wir sagen: Erregende Reize vom Magen und Ileum zum Uterus werden reflectorisch durch den Splanchnicus auf centripetaler, durch den Hypogastricus in erster und den Spermaticus in zweiter Linie auf centrifugaler Bahn übertragen. Die beiden letztgenannten Nerven sind die motorischen Nerven des Uterus. Im Wesentlichen laufen sowohl die afferenten, receptorischen, wie die efferenten motorischen Fasern des Reflexbogens vom Colon zum Uterus im Hypogastricus. Isolirte Hypogastricus-Durchschneidung schwächt den Uterus, Durchschneidung des Hypogastricus im Verein mit Splanchnicus oder Spermaticus macht den Uterus für Reflexe vom Magen-Darmcanal aus fast oder yollkommen unzugänglich. Der Pelvicus ist bei den Magen-Darmcanal-Uterusreflexen, die man als entero-uterine Reflexe bezeichnen kann, nicht betheiligt.

Die Reflexbahn geht nicht, wie man a priori glauben könnte, durch das Rückenmark; sie kann nur im sympathischen Nervensystem verlaufen. Denn wenn ich das Rückenmark am 10. Brustwirbel, unterhalb der Eintrittsstelle des Splanchnicus durchschnitten (Fig. 17, Taf. VII) oder das ganze periphere Rückenmark vom 10. Brustwirbel an abwärts mit einem rauh gefeilten Eisendraht zerstört hatte, blieben die Reflexe vom Magen und den einzelnen Darmabschnitten auf den Uterus in unveränderter Stärke bestehen. Die Reflexe werden erst schwächer, wenn mit der Durchschneidung des Rückenmarks die der Hypogastrici verbunden wird (Fig. 18, Taf. VII). 
Ich stelle die Resultate der ausserordentlich mühsamen und complicirten Experimente zur besseren Uebersicht in der Tabelle zusammen. Die beiden ersten Reihen zeigen den uterinen Effect der blossen Nervendurchschneidung an. Aus den beiden letzten Reihen ist die Uteruswirkung von Magen-Darmreizen nach Durchschneidung der verschiedenen Nerven ersichtlich.

\begin{tabular}{|c|c|c|c|}
\hline Nervendurehschneidung & $\begin{array}{l}\text { Effect auf } \\
\text { den Uterus }\end{array}$ & $\begin{array}{l}\text { Erregender } \\
\text { Reiz im }\end{array}$ & Effect auf den Uterus \\
\hline Vagus & Hemmung & $\begin{array}{l}\text { Magen } \\
\text { Ileum } \\
\text { Colon }\end{array}$ & Erregung \\
\hline Splanchnieus & Erregung & $\begin{array}{l}\text { Magen } \\
\text { Ileum } \\
\text { Colon }\end{array}$ & $\begin{array}{l}\text { fast kein Effect } \\
\text { starke Erregung }\end{array}$ \\
\hline Pelvicus & Erregung & $\begin{array}{l}\text { Magen } \\
\text { Ileum } \\
\text { Colon }\end{array}$ & starke Erregung \\
\hline Hypogastricus & Erregung & $\begin{array}{l}\text { Magen } \\
\text { Ileum } \\
\text { Colon }\end{array}$ & $\begin{array}{l}\text { schwache Erregung } \\
\text { fast kein Effect }\end{array}$ \\
\hline Spermaticus & Erregung & $\begin{array}{l}\text { Magen } \\
\text { Ileum } \\
\text { Colon }\end{array}$ & starke Erregung \\
\hline $\begin{array}{l}\text { Splanchnicus } \\
+ \text { Pelvicus }\end{array}$ & - & $\begin{array}{l}\text { Magen } \\
\text { Ileum } \\
\text { Colon }\end{array}$ & $\begin{array}{l}\text { fast kein Effeot } \\
\text { Frregung }\end{array}$ \\
\hline $\begin{array}{l}\text { Splanchnicus } \\
+ \text { Hypogastricus }\end{array}$ & - & $\begin{array}{l}\text { Magen } \\
\text { Ileum } \\
\text { Colon }\end{array}$ & $\begin{array}{l}\text { kein Effect } \\
\text { fast kein Effect }\end{array}$ \\
\hline $\begin{array}{l}\text { Splanchnicus } \\
+ \text { Spermaticus }\end{array}$ & - & $\begin{array}{l}\text { Magen } \\
\text { Ileum } \\
\text { Colon }\end{array}$ & $\begin{array}{l}\text { fast kein Effect } \\
\text { starke Erregung }\end{array}$ \\
\hline $\begin{array}{l}\text { Pelvicus } \\
+ \text { Hypogastricus }\end{array}$ & - & $\begin{array}{l}\text { Magen } \\
\text { Ileum } \\
\text { Colon }\end{array}$ & fast kein Effect \\
\hline $\begin{array}{l}\text { Pelvicus } \\
+ \text { Spermaticus }\end{array}$ & - & $\begin{array}{l}\text { Magen } \\
\text { Ileum } \\
\text { Colon }\end{array}$ & starke Erregung \\
\hline $\begin{array}{l}\text { Hypogastricus } \\
+ \text { Spermaticus }\end{array}$ & - & $\begin{array}{l}\text { Magen } \\
\text { Ileum } \\
\text { Colon }\end{array}$ & $\begin{array}{l}\text { kein Effect } \\
\text { kein oder fast kein Effect }\end{array}$ \\
\hline $\begin{array}{l}\text { Rückenmarkdurchschnei- } \\
\text { dung am 10. Brustwirbel }\end{array}$ & - & $\begin{array}{l}\text { Magen } \\
\text { Ileum } \\
\text { Colon }\end{array}$ & starke Erregung \\
\hline $\begin{array}{l}\text { Rückenmarkdurchsehnei- } \\
\text { dung am 10. Brustwirbel } \\
+ \text { bilaterale Hypogastri- } \\
\text { eus-Durchschneidung }\end{array}$ & - & $\begin{array}{l}\text { Magen } \\
\text { Ileum } \\
\text { Colon }\end{array}$ & schwache Erregung \\
\hline $\begin{array}{l}\text { Rïekenmark-Ausbohrung } \\
\text { vom 10. Brustwirbel an } \\
\text { abwärts }\end{array}$ & - & $\begin{array}{l}\text { Magen } \\
\text { lleum } \\
\text { Colon }\end{array}$ & starke Erregung \\
\hline
\end{tabular}


Wenn aber das Rückenmark die intermediäre Strecke der Reflexbahn zwischen Magen-Darmcanal und Uterus (s. Fig. b) nicht bildet, so können sich die Reflexe nur in den prävertebralen Ganglien (Fig. e), Nervenzellen oder Nerven, d. h. innerhalb des autonomen, sympathischen Nervensystems, abspielen. Man muss das Reflexcentrum im Ganglion solare, mesentericum superius und vor Allem wohl im Ganglion mesentericum inferius und spermaticum suchen oder die postganglionären (Fig. d) oder präganglionären (Fig. e) Axonreflexe Langley's (28) annehmen.

Figur b.

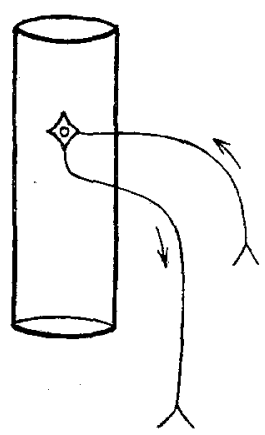

Reflex durch das Rückenmark.

Figur d.

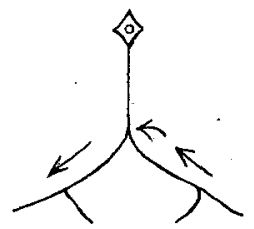

Postganglionärer Axonreflex (modificirt nach Langley's Abbildung)
Figur c.

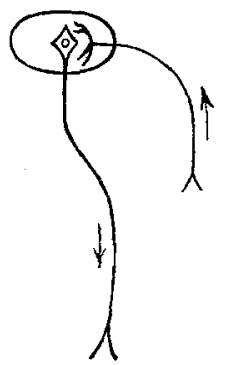

Reflex durch ein sympathisehes Ganglion.

Figur e.

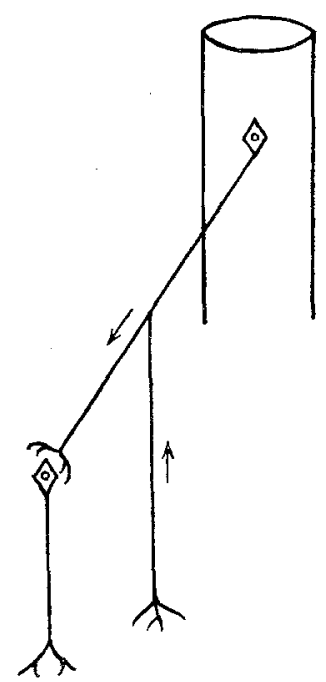

Präganglionärer homolateraler Axonreflex (nach Langley). 
Von postganglionären Axonreflexen redet Langley, wenn sich ein Reflex von einem Zweig eines von einer peripheren Nervenzelle abgegebenen Axons auf einen anderen Zweig desselben ohne diese Zelle zu passiren überträgt (s. Fig. d). Dann würde der Reflex z. B. vom Colon auf einem $Z$ weig des. Hypogastricus centripetal verlaufen, ohne das Ganglion mesentericum inferius zu erreichen, und auf einem anderen Ast des Hypogastricus zum Uterus gelangen. Bei der Besprechung der Topographie der Nerven wurde solcher Nerven, der von Lańgley nachgewiesenen lumbalen und hypogastrischen Colonfasern gedacht, die vom noch vereinigten Hypogastricusstamm zum Colon ziehen.

Präganglionäre Axonreflexe entstehen dann, wenn die präganglionäre Faser sich theilt und Zweige zu den einzelnen, am Reflex betheiligten Ganglien sendet. Ich bringe zum besseren Verständniss in Fig. e das von Langley angegebene Schema. Der präganglionäre Axonreflex würde vom Colon aus einer präganglionären Faser des Hypogastricus centripetal folgen, an einer Theilungsstelle der Faser centrifugalwärts auf einen anderen Zweig derselben Hypogastricusfaser, die eine peripher am Hypogastricus gelegene Ganglienzelle umspinnt, überspringen und, in dieser Ganglienzelle umgeschaltet, auf der von ihr peripherwärts ziehenden postganglionären Faser zum Uterus gelangen. Es ist klar, dass der ausgelöste präganglionäre Axonreflex homolateral oder contralateral, ungekreuzt oder gekreuzt sein kann, je nachdem alle Zweige der präganglionären Nervenfasern zu Ganglien der gleichen oder der entgegengesetzten Seite gehen. Das letztere, den Uebergang zu den Ganglien der Gegenseite, haben Langley-Anderson lür die Fasern nachgewiesen, welche zum Ganglion mesentericum inferius und den hypogastrischen Nerven verlaufen. Durch diese Kreuzung erklären sich die Versuchsergebnisse Sokownin's (29) und Langley - Anderson's (30). Jener fand, dass Reizung dos centralen Endes des vom Centrainervensystem isolirten Hypogastricus Contraction der Harnblase auf der entgegengesetzten Seite verursacht. Diese sahen ausserdem noch Contraction des Sphincter ani internus, Erblassen der Schleimhaiut des Rectums, Erblassen und Contraction des Uterushornes, der Cervix- und Vaginahälfte der Gegenseite.

Die prä- und postganglionären Axonreflexe könnten aber höchstens die Erklärung für die zwischen Colon und Uterus möglichen Reflexe abgeben. Die postganglionären Reflexe dürften schon 
deswegen abzulehnen sein, weil sie nach Langley selbst "nur einen sehr kleinen Bezirk beeinflussen", während hier zwischen Dickdarm und Uterus doch recht ausgedehnte Gebiete liegen. So bleiben nur die präganglionären Axonreflexe zur Erklärung mancher Colon-Uterusreflexe übrig. Die Mehrzahl dieser letzteren wird aber gleich allen anderen entero-uterinen Reflexen durch eines der grossen prävertebralen Ganglien den Weg nehmen. In ihnen erfolgt die Umschaltung des von der afferenten centripetalen Faser gebrachten Reizes auf die efferente motorische Faser; sie bilden dio Reflexcentren. Der Beweis dafür könnte im Einzelnen durch Exstirpation der verschiedenen prävertebralen Ganglien erbracht werden. Für die recto-uterinen Reflexe habe ich das Reflexcentrum bereits im unteren Mesenterialganglion nachgewiesen; nach Exstirpation desselben waren die Reflexe, wenn auch nicht vollständig, so doch nahezu verschwunden.

Einige Versuche sollten noch darüber orientiren, ob auch die hemmenden Reflexe vom Magen-Darmeanal auf den Uterus nach Ausschaltung der verschiedenen Nerven gleich den erregenden Reflexen eine Veränderung erfahren. Ich brauche im Einzelnen auf diese Experimente nicht einzugehen. Thre Ergebnisse decken sich mit den oben besprochenen. So bleibt der hemmende Reflex vom Magen auf den Uterus nach Anfüllung des Magens mit 300 -400 cem lauwarmem Wasser deutlich bestehen, trotz vorheriger Vagus-, Pelvicus- oder Spermaticus-Durchschneidung. Werden aber die Splanchnici oder Hypogastrici durchschnitten, so sind die hemmenden Reflexe vom Magen, Ileum oder Colon auf den Uterus nur sehr schwach.

\section{Ueber Reflexe von der Harnblase und den Ureteren auf den Uterus.}

Nach den vom Magendarmeanal auf den Uterus erhaltenen Reflexen durften solche auch von der Blase auf den Uterus erwartet werden. Diese Annahme war richtig.

Werden in die Harnblase grössere Mengen von indifferenten Flüssigkeiten injicirt, so dass eine Ausdehnung und Wandspannung erfolgt, so stehen die Uterusbewegungen für lange Zeit still; ja der Uterus, der vorher seine regulären Pendelbewegungen unaufhaltsam ausführte, kann viele Stunden lang, so lange der Versuch überhaupt andauert, in vollkommener Ruhe verharren. In wenigen Fällen erfolgte aber nach längerer Zeit eine beträchtliche Ver- 
kleinerung der Blase sowie eine erneute Thätigkeit der Uterusmusculatur; dann trieb die Harnblase ihren Inhalt durch die Urethra aus, und die Blasencontractionen erzeugten reflectorisch solche des Uterus. Wir haben hier ausnahmsweise dieselben Erscheinungen, wie wir sie oben für den Magen regelmässig constatirten. Das erklärt sich wohl durch die immerhin sehwächeren Contractionen der Blasenwand, durch die Unmöglichkeit der zur Blasenentleerung nothwendigen Bauchpressenaction am laparotomirten Thier sowie vielleicht durch die Enge der Urethra.

Werden Blasencontractionen durch mechanische oder chemische Reize ausgelöst: durch Kneifen der Wand der leeren oder wenig gefüllten Harnblase mit der Klemme oder der Pincette oder durch Eisenchlorid-, Ferropyrin- oder Silbernitratlösungen, die in geringer Concentration und in kleinen Mengen ( $1-3$ ccm einer $1-3$ proc. Lösung) in die Blase injicirt werden, so erfolgt eine intensive Verstärkung der Uterusbewegungen. Der Effect auf die Blase wurde in einigen Versuchen dadurch besonders kenntlich gemacht, dass von der Bauchhöhle aus in die Blase eine graduirte, unten mit einem tellerförmigen Ansatz versehene Pipette von $1 \mathrm{ccm}$ Inhalt in $1 / 100$ getheilt, nacb Art eines Manometers eingebunden und mit. physiologischer Kochsalzlösung oder Ringer'scher Flüssigkeit gefüllt wurde. Eine dünnere Glasröhre, rechtwinkelig abgebogen und graduirt, wurde einige Male auch durch die Urethra in der Blase fixirt. Aus dem Steigen oder Sinken des Flüssigkeitsspiegels war die Contraction oder Erschlaffung der Blase ebenso gut wie die graphische Registrirung der Uterusbewegungen erkennbar.

Dass bei dieser Versuchsanordnung eine Berührung zwischen Blase und Uterus vermieden werden muss, ist eine selbstverständliche Forderung. Ihr kann man entweder dadurch genügen, dass vor dem Versuch das Blasenperitoneum mit einem Faden an einer benachbarten Hautstelle locker fixirt wird, oder dass man das Thier senkrecht in eine nach Art eines hohen viereckigen Kastens construirte Zinkblechwanne aufstelit.

Auch $z$ wischen Ureteren und Uterus sind reflectorische Beziehungen nachweisbar [E. Kehrer (32)]. Auf Dilatation eines Ureters durch Wasser oder physiologische Kochsalzlösung von Körpertemperatur erfolgt in der Regel eine Hemmung, zuweilen aber eine Erregung der Uterusbewegungen. Sind diese Versuchsresultate auch nicht ganz so constant wie bei der Blase, so wurde doch auch hier niemals eine Reflexwirkung vermisst. 
Regelmässig dagegen wurde eine Verstärkung der Uterusbewegungen erzielt, wenn ein Ureter oder beide Ureteren mechanisch durch die Pincette oder durch Durchschneidung oder chemisch durch Injection eines halben Cubikcentimeters einer 5 proc. Argentum nitricum-Lösung gereizt wurden.

Die angegebenen Versuche zeigen, dass Dilatation der Blase und Ureteren reflectorisch eine Hemmung, Contraction der Blase und Ureteren dagegen bezw. sensible Reize an Blase und Ureteren eine Erregung der Uterusbewegungen herbeiführen. Die erstgenannte Erscheinung ist der experimentelle Beleg für die bekannte Thatsache, dass bei lange gefüllter Harnblase im Wochenbett eine Erschlaffung, Neigung zu Blutung, ungenügende Rückbildung und Retroflexion des Uterus zu entstehen pflegt.

Wie bei den entero-uterinen habe ich auch bei den vesicouterinen Reflexen die in Anspruch genommene Nervenbahn untersucht. Dass durch Durchtrennung der N. spermatici die Reflexe nicht verändert werden (2 Versuche), war bei dem Verlauf und der immerhin untergeordneten Bedeutung dieser Nerven gegenüber den Hypogastrici wohl zu erwarten. Bei der sensiblen wie motorischen Innervation der Blase durch den Hypogastricus sowohl wie den Pelvicus müsste die Unterbrechung der Reflexbahn zwischen Blase und Uterus möglich sein durch Ausschaltung eines dieser beiden Nervenpaare. Das ist merkwürdiger Weise nicht der Fall. Ja selbst nach combinirter bilateraler Durchschneidung der beiden Nervi hypogastrici und pelvici oder nach Ausbohrung des unteren Rückenmarks erleiden die reflectorischen Beziehungen zwischen Blase, Ureteren und Uterus keine wesentliche Einbusse. Nur nach Durchtrennung aller Sacralwurzeln - einer immerhin eingreifenden Operation - sind die vesico-uterinen Reflexe sehr schwach, was wohl durch Shockwirkung erklärt werden muss.

In 2 Versuchen zeigte sich noch eine geringe Erregung beider, gleichzeitig ihre Bewegungen registrirenden Uterushörner nach bilateraler Durchschneidung aller Sacralwurzeln und der Hypogastrici auf Injection von nur $1 \mathrm{ccm} 1$ proe. $\mathrm{AgNO}_{3}$ in die Blase; in diesen Fällen war nicht nur die Blase und der Uterus, sondern vor Allem auch das Rectum so contrahirt, dass die Wand des letzteren weissanämisch und verdickt war. Dadurch ist bewiesen, dass alle Beckenorgane, Blase, Uterus und Rectum bei ihren Be- 
wegungen in einer gewissen Abhängigkeit von einander stehen.

Wieder sind es die postganglionären oder wahrscheinlicher die präganglionären Axonreflexe Langley's, die für die Fortdauer der vesico-uterinen Reflexe nach Ausschaltung der Pelvici und Hypogastriei verantwortlich gemacht werden können. Oder man hat das Centrum des Reflexbogens zwischen Blase und Uterus in die den Plexus vesicalis bildenden äusseren und inneren Vesicalganglien de Lee's und Frankenhäuser's oder in die Frankenhäuserschen Cervicalganglien zu verlegen. Einen localen Reflexmechanismus in den Ganglien des Plexus vesicalis oder der Blasenwand nehmen nach Angabe Roith's L. R. Müller, Gaule, Griffith, v. Zeissl und Roith für den Beginn der Blasenentleerung in Anspruch.

\section{Die Reflexe von der Brustdrüse auf den Uterus}

haben merkwürdiger Weise bisher von allen Reflexen allein das Interesse der Kliniker gefunden. Vom Kliniker wurde die physiologische Erscheinung, dass durch Saugen des Kindes oder durch Melken Uteruscontractionen ausgelöst werden können, therapentisch verwerthet und durch Saugapparate die künstliche Frühgeburt provocirt oder die Dysmenorrhoe zu heilen versucht [Polano (32a)]. Waren auch diese Methoden in einigen Fällen von Erfolg begleitet, ihrer Unzuverlässigkeit wegen hat man sie allgemein verlassen, und der Skeptiker darf wohl annehmen, dass die wenigen Erfolge auf psychische Einflüsse zurückzuführen sind. Analogien dazu finden sich in der Geschichte der Wehenmittel, insbesondere der Mutterkornpräparate, von denen die werthlosesten oft von den glänzendsten Erfolgen am Kreissbett begleitet sein sollten, zur Genüge; und wenn man hört, dass es dem alten Friedrichs (33) gelang, durch Sinapismen von der Brust aus Wehen auszulösen, wird man in dieser Annahme nur bestärkt.

Was sagt nun zu diesen klinischen Angaben das physiologisehe Experiment?

Schlesinger (34), Max Pfister (4) und Kurdinowski haben allein die Reflexe zwischen Brustdrüse und Uterus untersucht. Schlesinger hat auf elektrische Reizung der Brustwarzen Uteruscontractionen beobachtet, welche in ihrer Intensität wẹit hinter dem uterinen Effect directer Reizung der centralen Enden 
peripherer Rückenmarksnerven zurückblieben. Er hatte an jungen Kaninchen mit schlecht entwickelten Brustdrüsen experimentirt.

Weit stärkere Reize verwendete Max $\mathrm{Pfister,} \mathrm{als} \mathrm{er} \mathrm{unter}$ F. A. Kehrer's und Cohnheim's Leitung bei einem Kaninchen, bei dem or die Peritonealhöhle eröffnet und eine erwärmte Glasschale in die Bauchwand eingesetzt hatte, ein Auvard'sches Saugglas mit einer Luftpumpe in Verbindung brachte. Trotz der sehr starken, von reichlichem Milchabfluss begleiteten Saugwirkung will Pfister bei der Betrachtung mit blossem Auge keine Verstärkung der Uterusbewegungen beobachtet baben. Das Thier hatte erst 3 Tage zuvor geboren.

Ein gleiches negatives Ergebniss hatte ein analoges Experiment Pfister's bei einem Kaninchen am 13. Tag nach der Geburt, sowie ein Versuch bei einem 3 Tage p. p. befindlichen Thier, bei dem ein über einen elastischen Katheter gebundener Gummiballon in ein Uterushorn eingeführt und mit einem Marey'schen Tambour in Verbindung gebracht wurde.

Auch Kurdinowski bezeichnet die Contractionen als schwach, die er auf mechanische Reizung der Brustwarzen mit dem Finger oder der Pincette, also auf geringe Reize hin, erbielt. Er experimentirte an nichtschwangeren Kaninchen, die er mit eröffneter Bauchhöhle in eine feuchte Kammer gebracht hatte.

Bei meinen Untersuchungen über Mamma-Genitalreflexe war die Reflexerregbarkeit der Thiere durch die Decerebration von vornherein gesteigert. Es bedurfte daher nicht so gewaltiger Reize, wie sie bei der Saugung durch die Luftpumpe in Pfister's Versuchen zur Anwendung kamen. Nach Abschneiden und Abrasiren der Haare wurde eine gewöhnliche kleine Bier'sche Glasglocke mit Gummiballon auf eine der am meisten cranial gelegenen, über den Wasserspiegel noch vorragenden Brustwarzen aufgesetzt, und in 2 Versuchen liess ich die Jungen an der Brust des puerperalen Thieres saugen. Es erfolgte bei graviden und puerperalen Katzen stets ein motorischer Effect auf den Uterus (Taf. VIII, Fig. 21 u. 22). Aber immer waren, selbst bei Ammenthieren, die Reflexe von der Mamma auf den Uterus weit geringer, als die vom Magen-Darmcanal auf den Uterus. Bei Thieren, die sich weder in schwangerem noch in puerperalem Zustand befanden, waren die Reflexe sehr schwach - was durch die Kleinheit und die gegenüber der Schwangersehaft geringere Erregbarkeit der Brustwarzen erklärt 
werden könnte. Ist doch klinisch durch die erhöhten Sehnenund Hautreflexe und experimentell durch die Versuche von Blumreich, bei denen Kreatin, auf die Grosshirnrinde trächtiger Kaninchen gebracht, Krämpfe viel leichter als bei nicht graviden Thieren auslöste, eine gesteigerte Reflexerregbarkeit des graviden Organismus nachgewiesen.

Ich komme demnach zu ähnlichen Resultaten wie'Schlesinger und Kurdinowski: Die Mamma-Genitalreflexe sind im Thierexperiment schwach, weit schwächer, als man allgemein glaubt, und wesentlich sehwächer als die enterouterinen Reflexe. Nur beim puerperalen Thier sind sie deutlich erkennbar. Meine Untersuchungen über Reflexe von Magen, Darm, Harnblase, Ureteren, peripheren Nerven, Haut und Schleimhäuten auf den Uterus haben in mir die Ueberzengung gefestigt, dass die Brustdrüsen die vielgerühmten specifischen Beziehungen $z u$ den Uteruscontractionen nicht besitzen. Ich stimme in diesem Punkt mit Kurdinowski überein. Könnten wir am Darm und vor Allem am Colon so häufige und starke Reize anbringen, wie sie durch den Saugact an den Mammae im Puerperium erfolgen, so müsste die Gebärmutter zu weit energischeren reflectorischen Contractionen gebracht werden. So kommen auch diese Versuche zu dem besonders von englischen Physiologen vertretenen Standpunkt, dass besondere nervöse Beziehungen zwisehen Brustdrüse und Uterus nicht existiren.

Denn auch das Wachsen der Brustdrüsen während der Schwangerschaft und die Schwellung während der Menstruation können nicht mehr vom Cterus oder im Sinne Pflüger's vom Ovarium ausgelöst und reflectorisch durch das C. N. S. vermittelt angesehen werden. Zeigen doch die Brustdrüsen in der Schwangerschaft wie im Wochenbett die volle Function auch nach Exstirpation des lumbo-sacralen Marks [Goltz u. Ewald (36)] oder der verschiedenen Theile des Bauchsympathicus [Basch (37)], oder nach Isolirung der Brustdrüsen vom Nervensystem durch Resection aller (?) zu ihnen führenden Nervenäste (Max Pfister). Ja, nachdem Ribbert (38) die Brustdrüsen bei 2 Tage alten Meerschweinchen exstirpirt und in eine künstlich erzeugte Hauttasche des Ohres. transplantirt hatte, war der Eintritt der Schwangersehaft dieses Thieres von Vergrösserung der verpflanzten Brustdrüsen und von Milchsecretion begleitet. Die Hypertrophie der Brustdrüsen ist also kein nervöser, sondern ein chemischer Reflex, und es ist nur noch 
zweifelhaft, ob der chemische Reiz, das Brusthormon, um mit Bayliss und Starling (2) zu reden, in den Chorionzotten [Halban (39)] oder - wie Starling und Lane Claypon (40) auf Grund ihrer Extractinjectionen von Ovarial-, Uterus-, Placentarund Fötalsubstanz behaupten - im wachsenden Embryo oder an anderen Stellen des Körpers gebildet wird.

Die reflectorische Verstärkung der Uterusbewegungen könnte entweder durch Reizung der Endigungen der sensiblen Rückenmarksnerven oder der sympathischen Gefässnerven der Brustdrüse entstehen. Im ersteren Fall muss der Reflex durch das Rückenmark zu einem der den Uterus versorgenden sympathischen Nerven, Hypogastrici oder Spermatici gelangen. Im letzteren Fall wird er wahrscheinlich durch das Vasomotorencentrum der Medulla auf die die Uterusgefässe umspinnenden sympathischen Nerven oder den Hypogastricus and Spermaticus übertragen; dann liegen Vasomotorenreflexe vor und die Contractionen des Uterus kommen durch die Veränderung in seinem Blutgehalt, durch die vorübergehende Anämie, zu Stande. Im Hypogastricus haben v. Basch-Hofmann und LangleyAnderson constrictorische Fasern für die Arterien von Uterus und Vagina nachgewiesen.

Ueber die afferente Bahn des Reflexes vermag ich keine Angaben zu machen. Die sensiblen Nerven; die an der Haut der Brust und der Brustwarze endigen, sind Aeste der Intercostalnerven: die Rami cutanei laterales pectoris, die von dem lateralen Rand des M. pectoralis major kommen, und die Rami eutanei anteriores pectoris, die in der Nähe der medianen Sagittalebene der Brust- und Bauchwand, also mehr distal von den vorigen, die Nn. intercostales verlassen. Ausserdem stehen die vom Leistenband aufsteigenden, angeblich vorzugsweise secretorische Fasern für die Brustdrüse führenden Nn. spermatici externi, sowie die Nn. thoracici longi mit der Brustdrüse in Verbindung. Eine Durchtrennung aller dieser Nerven ist kaum möglich. Und so versteht es sich, dass ich trotz Umschneidung der Brust noch Reflexe von der Brustdrüse auf den Uterus erbielt.

Die centrifugale Bahn des Reflexbogens untersuchte ich dadurch, dass ich die Saugpumpe an der Brust wirken liess nach bilateraler Durchschneidung der Nn. pelvici, hypogastrici und spermatici. Werden nur die Hypogastrici, nur die Spermatici oder nur die Pelvici ausgeschaltet, so erfahren die Reflexe keine Veränderung. Auch nach Durchschneidung aller 3 Nervenpaare, oder nach 
Ausbohrung des unteren Rückenmarks vom 10. Brustwirbel an bleiben die Reflexe auf den Uterus bestehen. Sie werden demnach vermittelt durch das obere Rückenmark und den Grenzstrang des Sympathicus oder durch das in der Medulla gelegene Vasomotorencentrum und die sympathischen Uterusgefässnerven.

\section{Reflexe von der Nase auf den Uterus.}

Der reflectorische Zusammenhang zwischen Nase und Uterus wird durch die Erregung des letzteren bewiesen, welche erfolgt, wenn die Nasenschleimhaut mit einem Streichhölzchen oder der Pincette mechanisch gereizt wird. Auch diese Uteruserregung ist schwächer als diejenige, die nach Magen-, Darm- oder Blasenreizen beobachtet wird. In einigen wenigen Fällen ging der Erregung ein kurzdauerndes Hemmungsstadium voraus. Andere Male erfolgte bei den gleichen Reizen von der einen Nasenhöhle aus Hemmung der Bewegungen beider Uterushörner, die ich bei fast allen Nasenreflexversuchen gleichzeitig ihre Contractionen graphisch registriren liess. Ich kann daher nicht von ganz constanten Ergebnissen sprechen. Der Reflexvorgang scheint ein complicirter zu sein.

Die Amann'sche Beobachtung beim Menschen, dass bei Reizung der unteren Muschel eine halbseitig gekreuzte Contraction des Uterus sammt dem entsprechenden Lig. rotundum eintritt, vermag ich auch für das Thier zu bestätigen. Mit einer durchgehenden Erscheinung haben wir es aber nicht zu thun. Vielmehr werden häufiger homolaterale und bilaterale als contralaterale Uterusreflexe gefunden.

Tabakrauch in die Nase eingeblasen, hat keinen Effect auf den Uterus. Die Pharmakologen bedienen sich bekanntlich dieser Methode u. a., um reflectorischen Glottisschluss hervorzurufen.

Ammoniakeinträufelung in die Nase führt zur Hemmung der Uterusbewegungen. Diese ist vielleicht trotz der künstlichen Respiration durch eine Veränderung der Athmung entstanden, also nicht als directer Beflex aufzufassen.

Complicirt gestaltete sich die Untersuchung des Reflexbogens. Weder durch Durchschneidung eines der 3 Uterusnervenpaare: der Pelvici, Hypogastrici und Spermatici, noch durch Ausbohrung des Rückenmarks vom 10. Brustwirbel an abwärts werden die NaseUterusreflexe beeinträchtigt. ( $\mathrm{Je} 2$ Versuche.) In 3 Versuchen durehschnitt ich sogar alle Sacralwurzeln und gleichzeitig die beiden hypogastrischen und spermaticalen Nerven, so dass der Uterus 
nur noch durch die Gefässnerven und durch die aus dem Grenzstrang kommenden Fäden mit den Resten des übrigen Nervensystems in Verbindung stand und doch waren in 2 von diesen Fällen noch leichte Reflexe von der Nasenschleimhaut auf den Uterus auslösbar. Damit ist der Beweis erbracht, dass die Reflexbahn wie bei den Mamma-Genitalreflexen im Wesentlichen durch den Sympathicus geht: von den sensiblen Rückenmarks- oder sympathischen Gefässnerven der Nase zum Vasomotorencentrum in der Medulla oder zu irgend einem sympathischen Ganglion und von diesem durch den Grenzstrang und durch die die Gefässe umspinnenden Vasomotoren zum Uterus. Diese letztere Annahme würde in Anlehnung an Experimente von Grützner und Heidenhain erklären, warum von der Nase aus das eine Mal Hemmung, das andere Mal Erregung des Cterus beobachtet wurde. Diese Forscher fanden nämlich, dass verschiedenartige sensible Hautreize ganz verschiedenartige Wirkungen auf den Blutdruck ausüben. Schwache kitzelnde Reize bewirkten Steigerung, starke mechanische oder chemische Schmerzreize bald Erniedrigung, bald Steigerung, bald keinen Effect. Die Erklärung ist die, dass direct den Nervenstamm oder seine nächste Umgebung treffende Reize stets den Blutdruck steigern, Reize, entfernt von sensiblen Nervenstämmen, keine oder erniedrigende Wirkung haben.

Auch die

\section{Reflexe von Haut und Schleimhäuten auf den Uterus}

dürften durch das sympathische Nervensystem auf die Vasomotoren der Uterusgefässe übertragen werden, weil sie nach Ausbohrung des unteren Rückenmarks oder nach combinirter Durchschneidung der Pelvici, Hypogastrici und Spermatici noch bestehen. Es ist bekannt, dass Reizung der Haut und der Schleimhäute verändernd auf den Blutgehalt der inneren Organe einwirkt. So erfolgt, um nur ein Beispiel zu bringen, bei schmerzhafter Reizung irgend einer Hautstelle Blässe des Gesichts.

Bringt man bei unserer Versuchsanordnung an einer Stelle der Haut, etwa am Ohr, einen energiseheren mechanischen Reiz an, z. B. durch starkes Kneifen mit der Pincette oder dem Finger, oder kitzelt man den Gehörgang mit einer Feder oder einem dünnen Streichhölzchen, oder combinirt man beim Ferrum candens den mechanischen mit einem thermischen Reiz, so erfolgt eine deutliche Verstärkung der Uterusbewegungen. 
Auch thermische Reize allein wirken erregend. Wird am nicht laparotomirten Thier in der oben geschilderten Weise experimentirt, dann dasselbe mit heissem oder sehr kaltem Wasser übergossen, oder auf die obere oder untere Körperhälfte eine heisse oder eiskalte Compresse aufgelegt, so registrirt der Schreibbebel verstärkte und beschleunigte, unter Umständen selbst tetanische Contractionen. Wir haben hierin wohl den experimentellen Beleg zu sehen für die bekannte Erscheinung, dass kurzdauernde heisse oder sehr kalte Voll-, Sitz- oder Fussbäder Schwangerschaftswehen auslösen oder eine Steigerung der vorhandenen Wehenthätigkeit bei der Geburt herbeiführen - eine Erscheinung, die beim Volke als Methode des criminellen Abortus Verwendung findet. Ich erinnere auch daran, dass man die heissen Vollbäder bei Eklamptisehen lange Zeit sowohl zur Anregung der Diaphorese und Diurese wie zur Verstärkung der Wehen gebrancht hat [Sippel (42)], und dass bei gewissen Hautreizen; wie bei plötzlicher Ablsühlung, Harndrang and Uteruscontractionen auftreten können.

Eine uterine Erregung wird ferner beobachtet bei subcutanen, übrigens auch bei intramusculären und intravenösen Injectionen. Darauf hat bereits Kurdinowski (35) bei seinen pharmakologischen Versuchen aufmerksam gemacht. Das Erheben der Hautfalte oder der Venencanüle oder das Einspritzen der indifferenten physiologischen Kochsalzlösung genügt zur Auslösung dieser reflectorischen Uteruserregung, an der auch der Blutdruck durch kurzdauernde Steigerung theilnimmt, wie fast alle meine Curven nach der Injection von Ergotin-, Hydrastis-, Cotarnin- und anderen Präparaten beweisen. Das momentane Einsetzen und der sehr flüchtige Charakter unterscheidet diesen reflectorischen Effect auf den Uterus von dem später einsetzenden und unendlich viel länger anhaltenden, der auf irgend ein Gift oder ein ehemisches Präparat erfolgt.

Dass auch von den Schleimhäuten aus Reflexe auf den Uterus erbalten werden können, zeigen neben den erwähnten Nasenversuchen diejenigen Experimente, bei denen die Mund- oder Rachenschleimhaut mechanisch gereizt oder mit dem Silbernitratstift oder mit concentrirter Carbolsäure verätzt wurde.

Gerade die Flüchtigkeit der Reflexe von Haut und Schleimhaut auf den Uterus und ihre geringe Intensität stimmt mit dem uterinen Effect nach Reizung der Brustwarzen und der Nase vollkommen überein. Das ist es, was mich zur festen Ueberzeugung bringt, dass - wie oben ausgeführt wurde - der Reiz von der 
Brust auf den Uterus nichts Specifisches darstellt, sondern nur ein Glied in der Kette der Reflexerscheinungen ist, die auf den Uterus erhalten werden können. Auch die Reflexbahn muss für Brustdrüse, Nase, Haut und Schleimhaut dieselbe sein; das zeigt sich in dem Erhaltenbleiben aller dieser Reflexe nach Ausbohrung des unteren Rückenmarks oder nach combinirter bilateraler Durchschneidung der N. pelvici, hypogastrici und spermatici. Der Reflexbogen führt in allen diesen Fällen entweder von den sensiblen Enden der Rückenmarksnerven oder den sympathischen Gefässnerven der Körperoberfläche zum oberen Rückenmark oder dem Vasomotorencentrum und durch den Grenzstrang oder die Vasomotoren zum Uterus. Ich bin überzeugt, dass auch von andern Hautpartien aus der puerperale Uterus genau ebenso gut mit geeigneten Reizmitteln zur Contraction gebracht werden kann wie von den Mamillen aus unter der Voraussetzung, dass diese Hautbezirke einen ähnlichen Nervenreichthum besitzen. $\mathrm{Zu}$ den wohl am stärksten mit Nerven versorgten Partien der Körperoberfläche gehört wohl die Haut des Gesichts und der Achselhöhle.

\section{Reflexe von peripheren Rückenmarksnerven auf den Uterus.}

Nachdem Claude Bernard von peripheren Nerven Reflexe auf ein Organ nachgewiesen hatte - nach Durchschneidung des Lingualis central von der Stelle, wo er die Chorda tympani abgiebt, führte elektrische Reizung des peripheren Endes des Lingualis Secretion der Submaxillardrüse herbei - durfte auch durch Reizung peripherer Rückenmarksnerven ein Effect auf den Uterus erwartet werden. Spiegelberg (43) sah auf elektrische Reizung des Vagus und Hypoglossus, Schlesinger (34) auf Reizung des centralen Stumpfes des N. medianus und cruralis sowie des Plexus brachialis, Röhrig (44) auf Reizung des centralen Stumpfes des N. cruralis und ischiadicus Uteruscontractiouen beim Kaninchen auftreten. Ich kann diesen Versuchen nur hinzufügen, dass auch durch mechanische Reizung des N. ischiadicus mit der Pincette oder durch Durchschneidung desselben eine uterine Erregung auszulösen ist. Dieselbe ist ebenso schwach und flüchtig wie diejenige, die von der Haut und Schleimhaut, von der Nase und Brustdrüse aus erhalten wird. Nach allen diesen Reflexversuchen kann es keinem Zweifel unterliegen, dass sich von allen sensiblen Nerven des Körpers reflectorisch Uteruscontractionen auslösen lassen. Dieses Gesetz haben Schlesinger 
und Oser bereits vermuthet, aber nur für die peripheren Rückenmarksnerven bewiesen. Das Reflexcentrum befindet sich dabei nicht - wie diese beiden Forscher behaupten - in der Grosshirnrinde, denn bei unserer Versuchsanordnung war das Grosshirn vom Rückenmark abgetrennt, sondern an irgend einer Stelle des obersten Rückenmarkes.

Die Ergebnisse der vorliegenden experimentellen Arbeit lassen sich in folgenden Schlusssätzen zusammenfassen:

1. Es sind Reflexe vom Magen-Darmcanal, von der Harnblase, den peripheren Rückenmarksnerven, der Haut und Schleimhaut auf den Uterus nachweisbar, und zwar am besten bei Thieren, bei denen die Reflexerregbarkeit durch die Decerebration, die Trennung des Grosshirns von den übrigen Theilen des O. N. S., erhöht wurde.

2. Am intensivsten erfolgt eine reflectorische Beeinflussung der Uterusbewegungen durch Reize, die im Magen oder Darm gesetzt werden. Am stärksten ist der Effect vom Colon auf den Uterus.

3. Auf die erregenden Magen-Darmreize antwortet der Uterus reflectorisch mit Erregung, d. h. mit einer Verstärkung und Beschleunigung seiner Contractionen unter Tonuszunahme. Den hemmenden Magen-Darmreizen folgt reflectorisch eine Hemmung der Uterusbewegungen, ein Ruhestadium unter Erschlaffung des Organs.

4. Zu den Reizen, die die Peristaltik des MagenDarmcanals beschleunigen und verstärken, gehören die mechanischen und chemischen Mittel, die von der Schleimhaut oder der Serosa aus wirken - am besten Silbernitrat in 1 proc. Lösung - , sowie kleine Mengen von Nahrungsmitteln und Flüssigkeiten. Hemmende Reize werden durch Dilatation des Magens oder der einzelnen Darmabschnitte mit reichlichen Flüssigkeitsmengen gesetzt.

5. Die reflectorische Parese der Uterusmuskulatur auf starke Füllung des Magens oder Darms entspricht der klinischen Erfahrung, welche in dem bekannten Wort: "Plenus venter non parit libenter" ihren Ausdruck findet.

6. Einige Zeit nach starker Magenfüllung nimmt der ruhende Uterus seine Bewegungen wieder auf, d. h. zu 
der Zeit, zu der der Magen seinen Inhalt in den Darm abgiebt und diesen zu lebhafterer Peristaltik veranlasst.

7. Ausser kleinen Mengen indifferenter Flüssigkeiten versetzen besonders die physiologisch im Magen und Darm thätigen und deren sensible Nerven und Peristaltik erregenden Reize den Uterus reflectorisch in eine energische Thätigkeit. $Z u$ diesen Reizen gehören die flüssigen Nahrungsmittel, wie Milch, concentrirte Zuckeroder Eiweisslösungen in kleinen Mengen, sowie von den Secreten die Salzsäure in der bei der normalen Verdauung vorhandenen Concentration, und ron den Verdaungsproducten die Peptone.

8. Die auffallend stark erregende Wirkung per os verabreichter Peptone auf die Uterusbewegungen ist zum Theil als Reflexvorgang vom Magen-Darmeanal aus anzusehen, zum Theil auf die Resorption des Peptons von Seiten des Dünndarms, also auf Peptonwirkung vom Blutweg aus zu beziehen. Intravenös injicirte Peptonlösungen wirken auf die Uteruscontractionen etwa ebenso stark wie Ergotinpräparate.

9. Die aufallend weitgehende Abhängigkeit der Uteruscontractionen von den sensiblen Reizen und vor allem den Bewegungen des Magen-Darmeanals kommt auch in der merkwürdigen Art der Beeinflussung des Uterus durch Eingabe einer 0,3 bis 0,5 proc. Salzsäurelösung in den Magen zum Ausdruck: Zuerst erfolgt für mehrere Minuten eine Erregung der Uterusbewegungen. An diese schliesst sich eine 5-10 Minuten anhaltende Ruhepause an. Dann tritt der Uterus für die Dauer von mehr als einer halben Stunde in ein Stadium sebr lebhafter Contractionen ein. Die erste Erregung ist die Folge des mechanischen Reizes bei der Injection und des chemischen Reizes der Salzsäure aul die Magenschleimbant. Die zweite Erregung setzt ein in dem Moment, da der Magen seinen Inbalt ins Duodenum abgiebt und die Darmperistaltik beginnt. Eine Ursache für die zwischen beiden Erregungsstadien liegende Ruhepause liess sich nicht nachweisen.

10. Die Experimente, welche die stark erregende Wirkung kleiner Peptondosen und spärlicher Chymus- 
mengen auf die Bewegungen des Magen-Darmeanals und des Uterus beweisen, zwingen zu klinischen Versuchen über die Beeinflussung der Wehenthätigkeit durch häufige kleine Dosen die Peristaltik anregender Nahrungsmittel, vor Allem durch Eiweissstoffe bezw. Peptone.

11. Jede Durchschneidung der dem autonomen System Langley's angehörenden Nerven ist von flüchtigem Einfluss auf die Uterusbewegungen. Auf Durchschneidung des Vagus oder Pelvicus, von denen jener dem cranialen, dieser dem sacralen autonomen System angehört, erfolgt schnell vorübergehende und geringgradige Hemmung der Uterusbewegungen. Durchtrennung der dem Sympathicus im engeren Sinne angehörenden Nerven, des Splanchnicus, Hypogastricus und Spermaticus ist von intensiver Erregung der Uteruscontractionen begleitet. Durch diese Versuche ist der Nachweis afferenter oder receptorischer Fasern im garzen autonomen System erbracht.

12. Die lebhaften Schmerzäusserungen auf Durchschneidung der sympathischen Nerven zeigon die bedeutsame Thatsache, dass der Sympathicus sensible Fasern besitzt. Diese kommen auch dem eranialen und besonders dem sacralen autonomen System, dem Pelvicus zu.

13. Die der Sympathicasdurchschneidung folgende allgemeine, in Bewegungen des Thieres sich offenbarende Erregung und die locale Erregung des Uterus sind Coëffecte der Reizung sensibler Nervenfasern. Eine Summation beider kommt in der Intensität der Uteruserregung zum A usdruck.

14. Sowohl die erregenden wie die hemmenden Reflexe können nach isolirter wie combinirter Durchschneidung der einzelnen Nervenpaare: der Splanchnici, Pelvici, Hypogastrici und Spermatici eine Aenderung erfahren.

15. Die afferente oder receptorische Bahn für erregende wie hemmende Reflexe geht vom Magen und Ileum durch den Splanchnicus, vom Colon durch den Hypogastricus; denn nach Durchschneidung der Splanchnici sind fast keine Reflexe vom Magen und Dünndarm auf den Uterus nachweisbar. Der Vagus ist bei den enterouterinen Reflexen nicht betheiligt. 
16. Der efferente oder centrifugale Abschnitt des Reflexbogens wird sowohl durch den Hypogastricus wie den Spermaticus - die beiden motorischen Nerven des Uterus - gebildet. Durch Durchschneidung eines dieser Nervenpare wird der Reflex geschwächt, aber nicht ausgelöscht.

17. Combinirte Durchtrennung des HypogastricusSpermaticus oder des Hypogastricus - Splanchnicus oder des Hypogastricus-Pelvicus machen den Uterus für Reflexe vom Magendarmeanal aus fast oder vollkommen unzugänglich, mag der letztere auch noch so stürmische Bewegungen zeigen.

- 18. Nach Pelvicusdurchschneidung bleiben die Reflexe vom Magen und Darm auf den Uterus unverändert bestehen.

19. Das Reflexcentrum für die entero-uterinen Beziehungen liegt nicht im Rückenmark, denn Rückenmarkdurchschneidung am 10. Brustwirbel, zwischen dem Ursprung der Splanchnicus- und Hypogastricusfasern, sowie Rückenmark-Ausbohrung rom 10. Brustwirbel an abwärts vermag die Intensität der Reflexe nicht zu stören.

20. Wegen weiterer Einzelheiten der unter No. 16-19 angeführten Thatsachen verweise ich auf den Text und die Tabelle S. 188.

21. Die intermediäre Strecke der Reflexbahn zwischen Magendarmcanal und Uterus kann nur im sympathischen System in den Zellen der grossen prävertebralen Ganglien: Ganglion coeliacum seu solare, Ganglion mesentericum superius und inferius, Ganglion renale und spermaticum seu ovaricum oder in den diese umgebenden sympathischen Nerven gesucht werden. Für die Colon-Uterusreflexe kommen ausserdem die präganglionären Axonreflexe im Sinne Langley's in Frage.

22. Erregende und hemmende Reflexe sind auch zwischen Harnblase und Ureteren einerseits und dem Uterus andererseits nachweisbar. Dilatation der Blase und Ureteren führt reflectorisch Hemmung, Contraction beider eine Erregung des Uterus berbei. Die reflectorische Parese ist der experimentelle Beleg für die bekannte Thatsache, dass bei lange gefüllter Harnblase im. 
Wochenbett eine Erschlaffung, Neigung zu Blutung, ungenügende Rüekbildung und Retroflexion des Uterus zu entstehen pflegt.

23. Wie bei den entero-uterinen wurde auch bei den vesico-uterinen Reflexen die in Anspruch genommene Nervenbahn untersucht. Ausschaltung eines der Uterus und Blase versorgenden Nervenpaare, der Hypogastrici oder Pelvici stört den Reflexmechanismus zwischen Blase und Uterus nicht. Selbst nach combinirter bilateraler Durchschneidung dieser Nerven erleiden die Reflexe keine Einbusse. Auch hier sind postganglionäre oder wahrseheinlicher präganglionäre Axonreflexe im Sinne Langley's oder "ganglionäre Reflexe" anzunehmen. 'Im letzteren Fall ist das Reflexcentrum in den Ganglienzellen der äusseren oder inneren Vesicalganglien oder den Frankenhäuser'schen Ganglien zu suchen.

24. Die Versuche über Blase-Cterusreflexe führten zu dem weiteren wichtigen Ergebniss, dass alle Beckenorgane: Blase, Uterus und Rectum bei ihren Bewegungen in einer gewissen Abhängigkeit von einander stehen können, derart, dass bei starken Bewegungen des einen Organes auch die beiden anderen sich intensiver contrahiren.

25. Die Reflexe von den Brustdrüsen auf den Uterus sind im Thierexperiment trotz künstlich gesteigerter Erregbarkeit des Centralnervensystems schwach, merkwürdiger Weise weit schwächer als man den Angaben der Geburtshülfe nach erwarten sollte und viel schwächer als die entero-uterinen Reflexe. Nur beim graviden und puerperalen Thier sind sie durch mechanische Reize, die durch Bier'sche Saugglocken oder durch das Saugenlassen der Jungen gesetzt werden, deutlich auslösbar.

26. Der afferente Abschnitt der Reflexbahn zwischen Brustdrüsen und Uterus ist nicht $z$ u bestimmen. Nach Durchschneidung der N. pelvici, hypogastrici oder spermatici oder nach Ausschaltung aller 3 Nervenpare oder nach Ausbohrung des Rückenmarkes vom 10. Brustwirbel an abwärts bleiben schwache Mammae-Uterusreflexe erhalten. Sie werden demnach vermittelt durch das obere Rückenmark und den Grenzstrang des Sympathicus oder durch das in der Medulla gelegene Vasomotoren- 
centrum und die sympathischen Uterusgefässnerven (Vasomotorenreflexe).

27. Die vielgerühmten specifischen nervösen Beziehungen zwischen Brustdrüsen und Uteruscontractionen lassen sich im Thierexperiment nicht nachweisen. Der Mamma-Genitalreflex bildet nur ein Glied in der Kette der Reflexerscheinungen, die von verschiedenen Organen und Nerven aus auf den Uterus erhalten werden können. Zwischen Brustdrüsen uud Genitalapparat existiren nur specifische chemische Correlationen.

28. Schwache Reflexe sind von der Nase auf den Uterus durch mechanische und chemische Reize auslösbar. Die Art der Beeinflussung ist inconstant. Homolaterale, contralaterale und besonders bilaterale Erregung der Uterushörner, in seltenen Fällen Hemmung des Uterus, kommen zur Beobachtung.

29. Durch mechanische und thermische Reize der Haut und Schleimbäute werden erregende Reflexe aut den Uterus erhalten - wodurch der wirksame Einfluss heisser und kalter Bäder auf die Wehen Erklärung findet.

30. Elektrische und mechanische Reizung sensibler Rückenmarksnerven, z. B. des Ischiadicus, führt reflectorisch Erregung des Uterus durch Vermittelung des Rückenmarkes herbei.

31. Zusammenfassend kann man sagen: Von allen sensiblen Nerven des Körpers, sowohl von den Rückenmarksnerven wie von dem nach den Ergebnissen unserer und Langley's Versuche mit sensiblen Fasern ausgestatteten Sympathicus lassen sich erregende Reflexe auf den Uterus erzielen.

32. Das Gemeinsame der Reflexe, die sich zwischen Haut, Schleimhaut, Nase, Brustdrüsen einerseits, dem Uterus andererseits abspielen, liegt in dem geringen Grad und der Flüchtigkeit der uterinen Erregung im Gegensatz zu den weit stärkeren und anhaltenderen Reflexen, die zwischen Harnblase und Uterus und besonders zwischen Magen-Darmcanal und Uterus beobachtet werden.

33. Die entero-uterinen und vesico-uterinen Reflexe gehen nur durch den vor der Brust-, Lenden- nnd Kreuz- 
beinwirbelsäule gelegenen Abschnitt des sympathischen Nervensystems. Die Reflexe von Haut, Schleimhaut, Nase, Brustdrüsen auf den Uterus bestehen noch nach Ausschaltung aller in das Becken eintretenden Nerven: der Hypogastrici, Spermatici und Pelvici sowie nach Ausbohrung des unteren Rückenmarkes vom 10. Brustwirbel an; es werden diese Reflexe von den sensiblen Endigungen der Rückenmarksnerven oder von den sympathischen Gefässnerven entweder durch das obere Rückenmark oder das Vasomotorencentrum der Medulla auf die den Uterus versorgenden sympathischen Nn. hypogastrici und spermatici oder auf die die Uterusgefässe begleitenden Vasomotoren übertragen. Bei diesen Vasomotorenreflexen erfolgen die Uteruscontractionen secundär durch Anämie. Die Reflexe von den Stämmen peripherer Rückenmarksnerven (Ischiadicus) werden durch das Rückenmark den motorischen Uterusnerven vermittelt.

\section{Literatur.}

1. B. Naunyn, Zur Lehre rom Husten. Deutsches Archiv f. klin. Medicin. Bd. 23. S. 423. 1879.

2. Bayliss u. Starling, Die chemische Coordination der Function des Körpers. Asher-Spiro's Ergebnisse der Physiologie. Wiesbaden 1906. Jahrg. V. S. 684 .

3. H. Busch, Das Geschlechtsleben des Weibes. Leipzig 1839.

4. Max Pfister, Ueber die reflectorischen Beziehungen zwischen Mamma und Genitalia muliebria. Hegar's Beiträge zur Geburtshilfe u. Gynäkologie. Bd. V. S. 421.1901.

5. Hippocrates' sämmtliche Werke, übersetzt von Upmann. I. Lehrsprüche. Citirt nach G. Mollath, Wiener med. Blätter. 1891. No. 11. S. 162.

6. Scanzoni, Beiträge zur Geburtshilfe und Gynäkologie. Bd. I. S. 15, 81,85 .

7. H. W. Freund, Ueber die Beziehungen der Schilddrüse und der Brustdrüse zu den schwangeren und erkrankten weiblichen Genitalien. Deutsche Zeitschr. f. Chir. Bd. 31. S. 446.

8. G. Mollath, Klinisch-experimentelle Untersuchungen über die wehenerregende und befördernde Wirkung des elektrischen Schröpf kopfes. Wiener med. Blätter. 1891. No. 11-15.

9. F. A. Kehrer, Ueber gastrische Wehenschwäche. Hègar's Beiträge zur Geb. u. Gynäk. Bd. 10. S. 148. 1906.

10. Walthard, von Winckel's Handbuch der Geburtshilfe. Bd.2. Th.3. S.2050. 
11. W. Fliess, Die Beziehungen zwischen Nase und weiblichen Geschlechtsorganen. Verlag Deuticke. S. 93.1897.

12. 0. Roith, Zur Innervation des Uterus. Monatsschr. f. Geb. u. Gyn. Bd. 25. H. 1. S. 93 .

13. Goltz, Ueber die Functionen des Lendenmarks des Hundes. Pflüger's Archiv f. Physiologie. Bd. 8. S. 460.1874.

14. Max Schrader, Zur Physiologie des Vogelhirns. Pflüger's Archiv. Bd. 44. S. 228.

15. E. Kehrer, Physiologische und pharmakologische Untersuchungen an den überlebenden und lebenden inneren Genitalien. Dieses Archiv. Bd. 81. S. 160 .

16. O. Cohnheim, Die Physiologie der Verdaung and Errnährung. Urban und Schwarzenberg. Berlin-Wien 1908.

17. F. Seiler, Deutsches Archiv f. klin. Med. Bd. 71. S. 269. 1901.

18. A. Velhaegen, cit. nach 0 . Cohnbeim. S. 63 .

19. Langley, Das sympathische und verwandte nervöse System der Wirbelthiere (autonomes nervöses System). Ergebnisse der Physiologie von Asher-Spiro. Bd. 2, H. 2. S. 818. 1903.

20. Frankenhäuser, Die Nerven der Gebärmutter. Jena 1867.

21. Langley-Anderson, Journal of physiol. Vol. 18. p. 122. Part IV. The internal generative organs. 1895.

22. de Lee, Philosophical Transactions. 1841 and 1842.

23. Ph. Jung, Untersuchungen über die Innervation der weiblichen Genitalorgane. Monatsschr. f. Geb. u. Gyn. Bd. 21. S. 1. 1905.

24. Langley-Anderson, Journal of Physiol. Vol. 19. p. 383. 1895-96. Part VI. Bistological and physiological observations upon the effect of section of the sacral nerves.

25. R. Magnus, Die Bewegungen des Verdauungsrohres. Ergebnisse der Physiologie von Asher-Spiro.

26. Langley-Anderson, Journal of Physiology. Vol. 17. p. 185.1894.

27. Langley-Anderson, Journal of Physiology. Vol. 19. p. 377. 1896.

28. Langley-Anderson, Journal of Physiology. Vol. 25. p. 364.1900.

29. N. Sokownin, Beiträge zur Physiologie der Entleerung und Zurückhaltung des Harns. Aus dem physiologischen Laboratorium der Kasaner Universität. Kasaner Universitäts-Nachrichten. 1877.

30. Langley-Anderson, Journal of Physiology. Vol. 16. p. 410. 1894.

31. Langley, Asher-Spiro's Ergebnisse der Physiologie. II. 2. 1903. S. 861.

32. E. Kohrer, Zeitschrift für gynäkologische Urologie. 1909. Bd. I. No. 6.

32a. Polano, Vortrag in der Nürnberger med. Gesellschaft. Ref. Münchener med. Wochenschr. 1908. S. 1859.

32 b. O. Roith, Welche Schädigungen ihres Gefäss- und Nervenapparates verträgt die Blase ohne dauernden Nachtbeil? Hegar's Beiträge für Geb. u. Gyn. Bd. 11. S. 126.

33. Friedrichs, De nuova quadam partus praematuri celebrandi methodo. Dissert. Rostock 1839. Cit. nach Mollath.

34. W. Schlesinger, Reflexbewegung des Uterus. Stricker's med. Jahrbuch. Bd. 1. 1873. 
35. Kurdinowski, Ueber die reflectoriseben Wecbselbeziehungen zwischen den Brustdrüsen und dem Uterus und über die wichtige Rolle der reflectorischen Einflüsse im Allgemeinen, sowohl in der Physiologie, als auch in der Pathologie des graviden und nicht graviden Uterus. Dieses Archiv. Bd. 81 . S. 340 .

30. F. Goltz u. R. Ewald, Pflüger's Archiv. Bd. 63. S. 385.

37. K. Basch, Ergebnisse der Physiologie. Bd. 1. S. 325. 1903.

38. H. Ribbert, Ueber Transplantation von Ovarium, Hoden und Mamma. Arohiv für Entwicklungsmechanik. 1898.

39. Halban, Dieses Arehiv. Bd. 72. 1905.

40. Lane-Claypon and Starling, Proc. Roy. Soc. T. 77. p. 505.1906.

41. P. Grützner a. Hoidenhàin, Pflüger's Archiv für Physiologie. Bd. 16.

42. Sippel, Die wehenerregende Wirkung heisser Vollbäder. Centralblatt für Gynäkologie. 1885̌. S. 693 .

43. Spiegelberg, Experimentelle Untersuchung über die Nervencentren und die Bewegung des Uterus. Zeitschr. f. rationelle Medicin. III. R. Bd. 2. 1858.

44. Röhrig, Experimentelle Untersuchungen über die Physiologie der Uterusbewegungen. Virchow's Archiv. Bd. 76 .

\section{Erklärung der Abbildungen auf den Tafeln III-VIII.}

Figur 1. (Versuch 12.2.08.) Spontanbewegungen des Kaninchenuterus. Das Thier erhielt vor dem Versuch $27 \mathrm{ccm} 10$ proc. Urethan per os durch die Schlundsonde zur Narkose. Bei $\uparrow$ Kneten einer prolabirten Dünndarmschlinge ohne jede Peritonealzerrung. Darauf schnell vorübergehende Verstärkung der Uterusbewegungen.

Figur 2. (Versuch 15. 1. 08.) Linkes Uterushorn der Katze. Aethernarkose. Auf zweimalige energische mechanische Reizung des Magens an der grossen Curvatur mit der Pincette lang anhaltende Erregung des Uterus. Der zweite am Dünndarm gesetzte Reiz ist wirkungslos.

Figur 3. (Versuch 10. 10. 08.) Enthirnte und unter künstlicher Respiration stehende Katze - wie in allen von nun an folgenden Versuchen -. Auf Injection von $15 \mathrm{ccm}$ einer 2 proc. $\mathrm{AgNO}_{3}$-Lösung in den leeren Magen erfolgt etwa 3 Minuten später eine ausserordentlich intensive, theilweise tetanische Uteruscontraction. Gleichzeitig ist der Magen tetanisch contrahirt, der ganze Dünndarm in lebhaftesten peristaltischen Bewegungen begriffen.

Figur 4. (Versuch 14. 10. 08.) Automatische Uteruscontractionen der Katze mit aufgesetzten Athembewegungen. Die reflectorisohe uterine Erregung geht parallel der Intensität der Darmbewegungen, die durch Injection von $20 \mathrm{ccm}$ einer 2 proc. $\mathrm{AgNO}_{3}$-Lösung in den Dünndarm ausgelöst werden.

Figur 5. (Versuch 15. 10. 08.) Enorme refiectorische Erregung der Uteruscontractionen auf Injection von $10 \mathrm{ccm}$ einer 1 proc. Silbernitratlösung in das leere Colon.

Figur 6a und b. (Versuche vom 3.6.09 und 20. 10.08.) Injection grosșer Flüssigkeitsmengen durch die Schlundsonde in den Magen führt zu 
Dehnung der Magenwände und somit reflectorisch zu längere Zeit (10 Winaten etwa) anbaltender Uterushemmung. Sobald der Magen seinen Inbalt in den Darm abgiebt und an diesem eine gesteigerte Peristaltik, Gefässinjection und zunehmende Füllung bemerkbar wird, zeigt auch der Uterus eine beträchtliche Verstärkung seiner Contractionen.

Figur 7. (Versuch 22. 7. 09.) Frischpuerperale Katze. Bei $\uparrow$ werden $20 \mathrm{ccm}$ einer concentrirten Rohrzuckerlösung durch die Schlundsonde in den Magen eingegeben. Dadurch reflectorisch eine energische uterine Erregung, entsprechend dem dem frischpuerperalen Organ eigenthümlichen Bewegungsiypus.

Figuren $8 \mathrm{a}$ and b. (Versuche rom 24.10. 08 und 21. 10. 08.) Auf Eingabe verdünnter $\mathrm{HCl}$ in den Magen - wie sie der Concentration bei der Magenverdauung yon Mensch oder Katze entspricht - erfolgt reflectorisch erst mässige Erregung, dann Hemmung, dann starke Erregung des Uterus.

Figuren $9 \mathrm{a}$ und b. (Versuche vom 22. 10.08 und 21. 10. 08.) Auf Eingiessen von Peptonlösung in den Magen erfolgt eine mässig starke, auf Injection derselben in den oberen Dünndarm eine ausserordentlich starke uterine Erregung.

Figur 10. (Versuch 16. 12. 08.) Auf bilaterale Splanchnicus-Darchreissung mässig starke Uteruserregung unter lebhaften Schmerzäusserungen des Thieres.

Figur 11. (Versuch 22. 10. 08.) Doppelseitige Hypogastricus-Durchschneidung führt zu kurzdauernder Hemmung, der sich eine langanhaltende Erregung des Uterus ansohliesst.

Figur 12. (Versuch 4. 11. 08.) Durch Vagus-Durchschneidung wird der reflectorisch die Uterusbewegungen anregende Einfluss von chemischen Magenreizen nicht gestört.

Figur 13. (Versuch 23. 4. 09.) Nach bilateraler Hypogastricus-Durchschneidung ist Injection von $10 \mathrm{~cm}$ einer 1 proc. $\mathrm{AgNO}_{3}$-Lösung ins Colon nur von minimaler Erregung des Uterus begleitet.

Figur 14. (Versuch 21. 10, 08.) Starke uterine Erregung auf Hypogastricus-Durchschneidung. Trotz der letzteren bleibt der Effect auf den Uterus erhalten nach Injection von $15 \mathrm{ccm} 1$ proc. Silbernitratlösung ins Colon.

Figur 15. (Versuch 27. 4. 09.) 'Trotz beiderseitiger Pelvicus- und Spermaticus-Durchschneidung erfolgt starke uterine Erregung auf Injection von $5 \mathrm{ccm} 1$ proc. $\mathrm{AgNO}_{3}$ ins Colon. Das Colon bewegt sich sehr lebhaft unter Ausstossung von Fäcalmassen und Gasen.

Figur 16. (Versuch 20. 4. 09.) Nach bilateraler Hypogastricus- und Spermatious-Durchschneiding lassen sich Reflexe vom Colon anf den Uterus nicht mehr nachweisen.

Figur 17. (Versuch 9. 4. 09.) Rückenmarkdurchschneidung in Höhe des 10. Brustwirbels, zwischen dem Ursprung der Splanchnicusfasern und der den Uterus versorgenden Nerven, stört den Reflexmechanismus des Uterus nach chemischen Colonreizen nicht.

Figur 18. (Versuch 23. 5. 09.) Rückenmarkdurchschneidung am 10. Brustwirbel und bilaterale Hypogastricus-Durchtrennung. Trotzdem noch schwache Erregung des Uterus nach Finspritzung von $5 \mathrm{~cm}$ einer 1 proc. Silbernitratlösung ins Colon. 
Figur 19. (Versuch 21. 5. 09.) Nach bilateraler Spermaticus-Durchschneidung bleiben chemische Reize der Harnblase stark wirksam auf den Uterus.

Figur 20. (Versuch 6. 8. 09.) Spätpuerperale Katze mit Milch in den hypertrophischen Brustdrüsen. Saugen an der Brust mit Bier'scher Glasglocke hat geringen reflectorischen Effect auf die Uterusbewegungen.

Figur 21. (Versuch 11.5.09.) Katze im Anfangsstadium der Schwangerschaft. Im rechten Uterushorn ein gut pflaumengrosser Fruchtsack. Linkes Uterushorn enthält keine Frucht. Dureh längeres Saugen an der am meisten cranial gelegenen linken Brustwarze wird ein mässig starker motorischer Effect am linken Uterushorn erreicht.

Figur 22. (Versuch 19.8. 09.) Beide Uterushörner eines spätpuerperalen Ammenthieres erfahren oine mässig starke reflectorische Erregung durch Ansaugen der I. linken Brustwarze mit der Saugpumpe. Graphische Registrirung beider Uterushörner.

Figur 23. (Versuch 3. 5. 09.) Mechanische Reizung der rechten und linken Nasenhöhle mit einem Streichhölzchen ist von starker Erregung des linken Uterushorns begleitet.

Figur 24. (Versuch 27. 4. 09.) Vor dem Versuch bilaterale Pelvicusund Spermaticus-Durchschneidang. Eirregende Wirkung mechanischer Nasenreizung auf den Uterus. 